\title{
Intercomparison exercise between different radiative transfer models used for the interpretation of ground-based zenith-sky and multi-axis DOAS observations
}

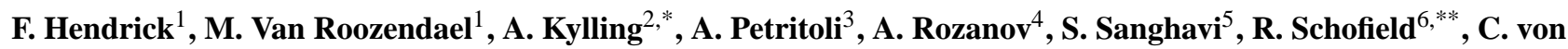 \\ Friedeburg $^{5}$, T. Wagner ${ }^{5}$, F. Wittrock ${ }^{4}$, D. Fonteyn ${ }^{1}$, and M. De Mazière ${ }^{1}$ \\ ${ }^{1}$ Institut d'Aéronomie Spatiale de Belgique, Brussels, Belgium \\ ${ }^{2}$ Norwegian Institute for Air Research, Kjeller, Norway \\ ${ }^{3}$ Institute of Atmospheric Science and Climate, Bologna, Italy \\ ${ }^{4}$ Institute of Environmental Physics, University of Bremen, Bremen, Germany \\ ${ }^{5}$ Institute of Environmental Physics, University of Heidelberg, Heidelberg, Germany \\ ${ }^{6}$ National Institute of Water and Atmospheric Research, Omakau, Central Otago, New Zealand \\ *now at: St. Olavs University Hospital, Trondheim, Norway \\ ** now at: NOAA Aeronomy Laboratory, Boulder, Colorado, USA
}

Received: 30 June 2005 - Published in Atmos. Chem. Phys. Discuss.: 2 September 2005

Revised: 29 November 2005 - Accepted: 13 December 2005 - Published: 20 January 2006

\begin{abstract}
We present the results of an intercomparison exercise between six different radiative transfer (RT) models carried out in the framework of QUILT, an EU funded project based on the exploitation of the Network for the Detection of Stratospheric Change (NDSC). RT modelling is an important step in the interpretation of Differential Optical Absorption Spectroscopy (DOAS) observations. It allows the conversion of slant column densities (SCDs) into vertical column densities (VCDs) using calculated air mass factors (AMFs). The originality of our study resides in comparing SCD simulations in multi-axis (MAX) geometry (trace gases: $\mathrm{NO}_{2}$ and $\mathrm{HCHO}$ ) and in taking into account photochemical enhancement for calculating SCDs of rapidly photolysing species $\left(\mathrm{BrO}, \mathrm{NO}_{2}\right.$, and $\left.\mathrm{OClO}\right)$ in zenith-sky geometry. Concerning the zenith-sky simulations, the different models agree generally well, especially below $90^{\circ} \mathrm{SZA}$. At higher SZA, larger discrepancies are obtained with relative differences ranging between $2 \%$ and $14 \%$ in some cases. In MAX geometry, good agreement is found between the models with the calculated $\mathrm{NO}_{2}$ and $\mathrm{HCHO}$ SCDs differing by no more than $5 \%$ in the elevation and solar zenith angle (SZA) ranges investigated $\left(5^{\circ}-20^{\circ}\right.$ and $35^{\circ}-85^{\circ}$, respectively). The impacts of aerosol scattering, ground albedo, and relative azimuth on MAX simulations have also been tested. Significant discrepancies appear for the aerosol effect, suggesting differences between models in the treatment of aerosol scattering. A bet-
\end{abstract}

Correspondence to: $\mathrm{F}$. Hendrick

(franch@oma.be) ter agreement is found in case of the ground albedo and relative azimuth effects. The complete set of initialization data and results have been made publicly available through the QUILT project web site (http://nadir.nilu.no/quilt/), enabling the testing of other RT codes designed for the calculation of SCDs/AMFs.

\section{Introduction}

Since the middle of the 1970s, stratospheric ozone and several trace gases directly or indirectly involved in the ozone depletion like $\mathrm{NO}_{2}, \mathrm{BrO}$, and $\mathrm{OClO}$ have been monitored from the ground using the Differential Optical Absorption Spectroscopy (DOAS)-technique (Platt, 1994). A significant part of this monitoring effort has been carried out through the framework of the Network for the Detection of Stratospheric Change (NDSC). The NDSC consists of about 75 globally distributed stations combining various observation techniques. The network operation started in January 1991 and has been providing a consistent, standardised set of longterm measurements of stratospheric and, more recently, tropospheric trace gases, particles, and physical parameters for detecting atmospheric change, validating space-borne sensors, and testing and improving multidimensional models of both the stratosphere and troposphere (further information at http://www.ndsc.ncep.noaa.gov/). Concerning the scattered sunlight DOAS instruments, they operated until recently

(C) 2006 Author(s). This work is licensed under a Creative Commons License. 
almost only in zenith-sky geometry, thus probing mainly the altitude region corresponding to the stratosphere, especially at large solar zenith angles (SZAs). Over the last decade, new instruments pointing not only at zenith but also towards the horizon (off-axis geometry) have been developed (e.g., Heckel et al., 2005; Hönninger et al., 2004; Wagner et al., 2004; Wittrock et al., 2004). Pointing at an elevation angle close to the horizon provides enhanced sensitivity to the troposphere compared to zenith-sky observations. The MultiAXis (MAX-) DOAS technique combines different elevation angles. Owing to the variation of the light paths in the troposphere with the elevation angle, the different viewing directions have maximum sensitivity at different altitudes, thus providing some information on the vertical distribution of the absorber.

An important step in the interpretation of DOAS observations is the conversion of the slant column densities (SCDs) - which are the direct product of the DOAS analysis - into vertical column densities (VCDs) using calculated air mass factors (AMFs). The AMF represents the ratio of the effective optical path through the atmosphere to the vertical optical path and is given by the ratio SCD/VCD (Noxon et al., 1979; Solomon et al., 1987). In practice, AMFs are calculated using a radiative transfer (RT) model. In case of short lived species such as $\mathrm{BrO}, \mathrm{OClO}$, and $\mathrm{NO}_{2}$, the calculation of SCDs and therefore AMFs is complicated by the variation of the concentration of these species along a given light path due to the fast diurnal variation of these radicals coupled to the local SZA variation along the light path (Fish et al., 1995). This so-called photochemical enhancement effect is taken into account by initializing RT models with a table containing the concentrations of the absorber for different altitudes and SZAs. This table is then interpolated to determine the trace gas concentrations at the altitudes and local SZAs of the different scatter points considered along a given sun ray path. Such a concentration table is usually generated by running a stacked box photochemical model initialized with the output of a 3-D chemical transport model (CTM) corresponding to the day and location of interest. SCDs calculated by coupling a 3-D CTM to a photochemical box-/RT model interface can also be directly compared to observed SCDs. For example, Sinnhuber et al. (2002) compared ground-based zenith-sky UV-visible observations of $\mathrm{BrO}$ obtained at 11 sites with simulations from the 3-D CTM SLIMCAT (Chipperfield, 1999). The RT model used was based on the single scattering ray tracing scheme of Solomon et al. (1987). Recently, several groups have initiated AMF calculations in order to interpret MAX-DOAS measurements. Hönninger et al. (2004) have studied the behaviour of AMFs as a function of the solar zenith, elevation, and relative azimuth angles, ground albedo, and aerosol loading for several idealized trace gas profiles. For this purpose, they have used the RT model TRACY based on a Monte Carlo approach (von Friedeburg, 2003). This model has been also used by Wagner et al. (2004) to perform RT modelling for MAX-DOAS $\mathrm{O}_{4}$ observations at different aerosol conditions. Sensitivity tests on $\mathrm{O}_{4}$ AMFs were carried out by Wittrock et al. (2004) with SCIATRAN, a RT code based on a combined differentialintegral approach involving the Picard iterative approximation (CDIPI) (Rozanov et al., 2000, 2001, 2005) and, as a first application, $\mathrm{NO}_{2}$ profile information were derived from MAX-DOAS observations. It should be noted that an accurate $\mathrm{RT}$ model as forward model is essential in the retrieval of tropospheric trace gas profiles using MAX-DOAS measurements (e.g., Bruns et al., 2004). In Heckel et al. (2005), the SCIATRAN model also generated appropriate AMFs for the conversion of MAX-DOAS measurements of HCHO into VCDs. These examples show that RT modelling plays a central role in the interpretation of ground-based DOAS observations and that different RT computation schemes are available for this purpose.

The QUILT (Quantification and Interpretation of LongTerm UV-Vis Observations of the Stratosphere) project is an EU funded project based on the exploitation of the NDSC and aimed at quantifying ozone loss and investigating its relation to active halogen and nitrogen species using the existing ground-based, satellite and balloon borne UV-visible data as well as 3-D atmospheric modelling tools. One of the tasks of this project has been to test the consistency between the different RT models existing within the consortium and used to interpret the ground-based and satellite DOAS data. This objective has been achieved through several SCD simulations comparison tests performed using identical settings for all the models. Both ground-based zenith-sky (trace gases: $\mathrm{BrO}, \mathrm{NO}_{2}$, and $\mathrm{OClO}$ ) and $\mathrm{MAX}$ geometries (trace gases: $\mathrm{NO}_{2}$ and $\mathrm{HCHO}$ ) have been considered for these tests, with photochemical enhancement being taken into account only in zenith-sky geometry.

Here we report on the results of this intercomparison exercise. It should be noted that our study does not address the issue of the absolute accuracy of the SCD calculations, the consistency between simulated and measured SCDs having already been tested in several papers (e.g., Sinnhuber et al., 2002; Tørnkvist et al., 2002). It can be considered to a certain extent as the continuation of Sarkissian et al. (1995) who calculated $\mathrm{O}_{3}$ and $\mathrm{NO}_{2}$ AMFs with different RT models in zenith-sky geometry but without taking into account the photochemical enhancement effect (use of a single profile for the initialization of the models). Our paper is divided into five parts. In Sect. 2, we describe the different RT models involved in the intercomparison exercise. The comparison tests in zenith-sky and MAX geometries are described in Sects. 3 and 4, respectively, and their corresponding results are discussed therein. Sects. 5 and 6 are dedicated to the impact of aerosols and ground albedo on MAX simulations, respectively. 
Table 1. Short description of the RT models involved in the intercomparison exercise. Note that both IASB and NILU models are based on the UVspec/DISORT package. However, they are not strictly identical since they have been adapted separately by each group in order to allow SCD/AMF calculations taking into account photochemical enhancement.

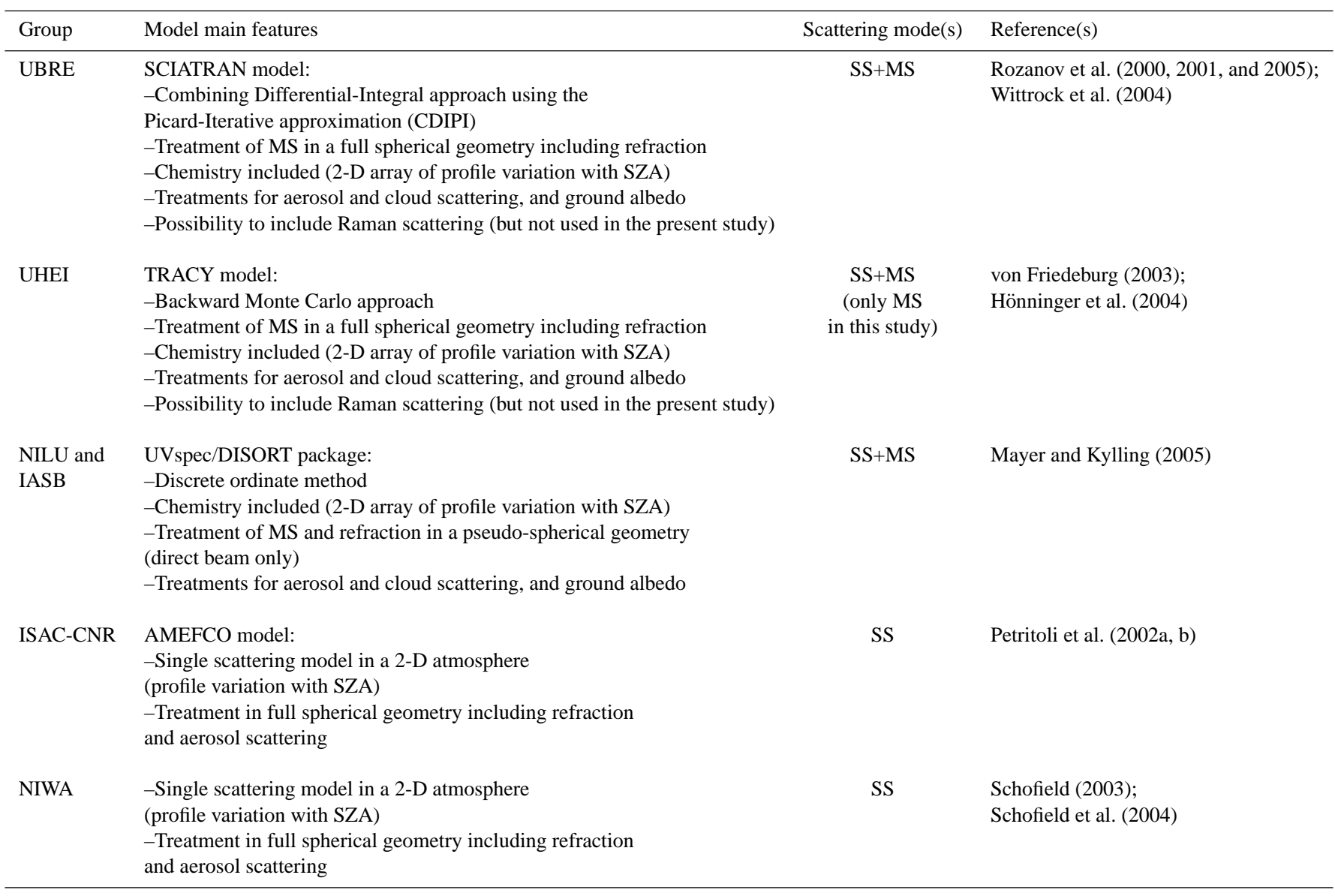

\section{Description of the RT models}

The groups contributing RT calculations to the intercomparison exercise were the remote sensing groups at the Universities of Bremen (UBRE) and Heidelberg (UHEI), the Norwegian Institute for Air Research (NILU), the Institute of Atmospheric Science and Climate (ISAC-CNR), the National Institute of Water and Atmospheric Research (NIWA), and the Institut d'Aéronomie Spatiale de Belgique (IASB). A summary of the characteristics of the models used by these groups is given in Table 1. From now on, each model will be referred to by the acronym of its corresponding group (in brackets here above). All models include the possibility of taking into account photochemical enhancement. The solution approaches to the RT equation (RTE) used in the different RT codes are as follows:

- The Combined Differential-Integral (CDI) approach (UBRE model): is based on the solution of the integral
RT equation using the characteristics method (Currant and Hilbert, 1962). The source function is integrated along the line of sight intersecting a spherical atmosphere. The single scattering part of the source function is calculated truly spherical and the multiple scattering part is initialized by the output of the pseudo-spherical model (Rozanov et al., 2000 and 2001).

- The Discrete Ordinate method (NILU and IASB models): the azimuth dependence of the radiation field is expressed as a Fourier cosine series in azimuth. The solution of the Fourier components is obtained using a numerical quadrature scheme, allowing to replace the integrals by sums and thus reducing the RTE to the solution of a set of coupled linear first-order differential equations (Lenoble, 1985; Stamnes et al., 1988; Spurr, 2001).

- The backward Monte Carlo method (UHEI model): a photon emerges from a detector in an arbitrary line of 


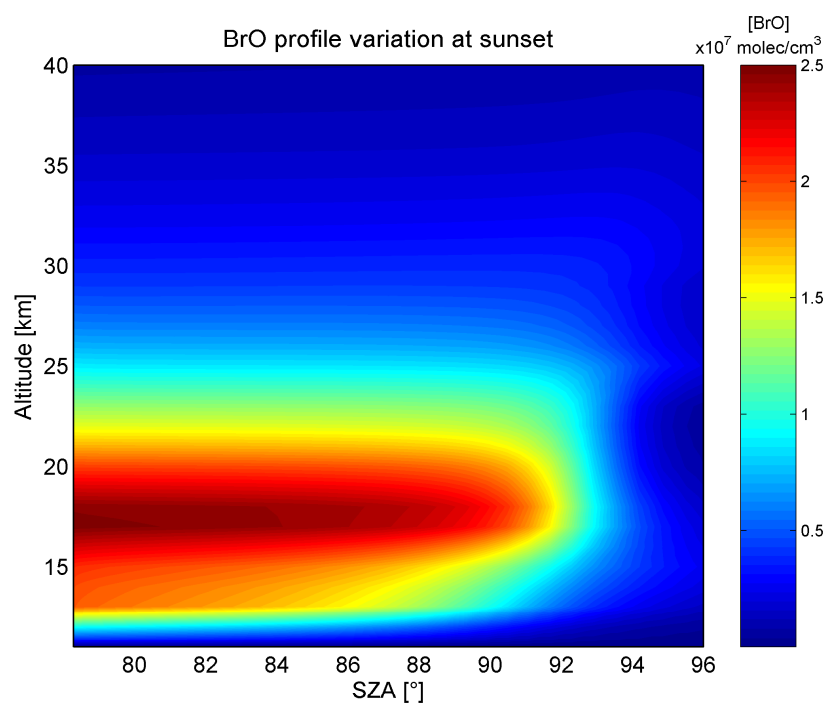

Fig. 1. Contour plot of the BrO profiles table used to initialize the models in the comparison test in zenith-sky geometry. The variation of the BrO profiles as a function of the SZA has been calculated for Harestua $\left(60^{\circ} \mathrm{N}\right.$, Norway) at sunset under chlorine activated conditions.

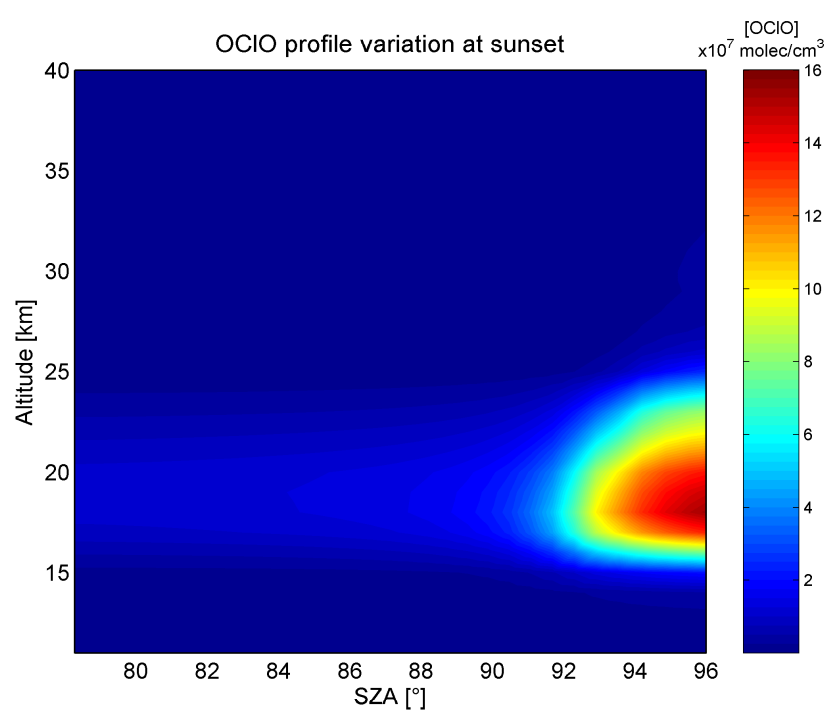

Fig. 2. Contour plot of the OClO profiles table used to initialize the models in the comparison test in zenith-sky geometry. The variation of the $\mathrm{OClO}$ profiles as a function of the SZA has been calculated for Harestua $\left(60^{\circ} \mathrm{N}\right.$, Norway) at sunset under chlorine activated conditions.

sight direction and is followed in the backward direction along the path towards the sun. The various events which may happen to the photon at various altitudes in the atmosphere are defined by suitable probability distributions. Random numbers decide on the occurrence of events. At the location of the last scattering event prior to leaving the atmosphere, the impinging radiance

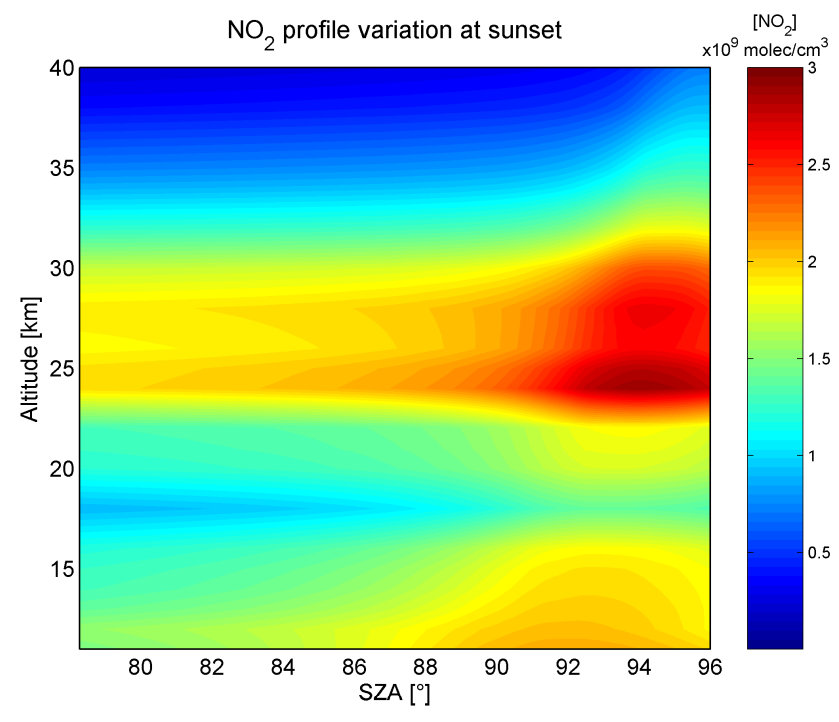

Fig. 3. Contour plot of the $\mathrm{NO}_{2}$ profiles table used to initialize the models in the comparison test in zenith-sky geometry. The variation of the $\mathrm{NO}_{2}$ profiles as a function of the SZA has been calculated for Harestua $\left(60^{\circ} \mathrm{N}\right.$, Norway) at sunset in summer.

is calculated and weighted with the value of the scattering phase function and with the attenuation of the complete path. A large number of such random photon paths will reproduce the light contributing to the simulated measurement (von Friedeburg, 2003; Lenoble, 1985).

- Single scattering ray tracing method (ISAC-CNR and NIWA models): in zenith-sky geometry, it consists of computing the attenuation from the sun through discrete spherical atmospheric shells to "points" where the light beams are scattered into the detector (Solomon et al., 1987).

\section{Zenith-sky simulations of $\mathrm{BrO}, \mathrm{NO}_{2}$, and OCIO SCDs including photochemical enhancement}

\subsection{Comparison test description}

In this test, $\mathrm{BrO}, \mathrm{OClO}$, and $\mathrm{NO}_{2} \mathrm{SCD}$ have been calculated in zenith-sky geometry in single scattering (SS) and, when possible, in multiple scattering (MS) modes, taking into account photochemical enhancement effect. The settings imposed for all models are summarized in Table 2. Contour plots of the diurnal variation tables (concentration of $\mathrm{BrO}, \mathrm{OClO}$, and $\mathrm{NO}_{2}$ as a function of altitude and SZA) are shown in Figs. 1, 2, and 3, respectively. They are the output of the stacked box photochemical model PSCBOX (Errera and Fonteyn, 2001; Hendrick et al., 2000 and 2004) initialized with the 3-D-CTM SLIMCAT chemical and meteorological fields. Two scenarios have been considered: Harestua $\left(60^{\circ} \mathrm{N}\right.$, Norway) at sunset in summer for $\mathrm{NO}_{2} \mathrm{SCD}$ 
Table 2. Model settings for the comparison test in zenith-sky geometry. All the initialization data are available on the QUILT web site (http://nadir.nilu.no/quilt/).

\begin{tabular}{ll} 
Altitude grid & $0-120 \mathrm{~km} / 1 \mathrm{~km}$ thick \\
Wavelength & $352 \mathrm{~nm}(\mathrm{BrO})$ \\
& $368 \mathrm{~nm}(\mathrm{OClO})$ \\
& $422 \mathrm{~nm}\left(\mathrm{NO}_{2}\right)$ \\
& From PSCBOX model \\
Diurnal variation table (see Figs. 1, 2, and 3) & From SLIMCAT 3-D-CTM; interpolation \\
p, T profiles & using AFGL 1976 outside the SLIMCAT \\
& altitude range \\
$\mathrm{O}_{3}$ profile & From PSCBOX model; interpolation \\
& using AFGL 1976 outside the SLIMCAT \\
& altitude range \\
$\mathrm{NO}_{2}$ profile (for BrO and OClO SCD calculations) & From PSCBOX model; interpolation \\
& using AFGL 1976 outside the SLIMCAT \\
& altitude range \\
Mie scattering & Not included \\
Refraction & Not included \\
Cross sections sets & BrO: Wahner et al. (1988) \\
& OClO: Wahner et al. (1987) \\
& NO $:$ Burrows et al. (1998) \\
& $\mathrm{O}_{3}:$ Burrows et al. (1999) \\
Ground albedo & 0.20 \\
Scattering mode & SS+if possible MS \\
\hline
\end{tabular}

calculations and Harestua at sunset under chlorine activated conditions for $\mathrm{BrO}$ and $\mathrm{OClO}$. All calculations included absorption by $\mathrm{O}_{3}$ and, in case of $\mathrm{BrO}$ and $\mathrm{OClO}$, also absorption by $\mathrm{NO}_{2}$.

\subsection{Results}

The results of the zenith-sky simulations of $\mathrm{BrO}, \mathrm{NO}_{2}$, and OClO SCDs are presented in Fig. 4. We first concentrate on the general behaviour of the simulated SCDs. Figure 4 shows that the impact of MS is more important for $\mathrm{BrO}$ than for $\mathrm{NO}_{2}$, and for $\mathrm{OClO}$, it is mostly significant at large SZA $\left(>92^{\circ}\right)$. The different behaviours of $\mathrm{BrO}$ and $\mathrm{NO}_{2}$ regarding MS effects can be mainly attributed to the different wavelengths used for both calculations $(352 \mathrm{~nm}$ for $\mathrm{BrO}$ and $422 \mathrm{~nm}$ for $\mathrm{NO}_{2}$ ). In case of OClO, the large impact of MS at SZAs larger than $\sim 92^{\circ}$ is related to the photochemistry of this species combined with geometrical considerations. Figure 2 shows that $\mathrm{OClO}$ is situated in the $\sim 17-22 \mathrm{~km}$ altitude range and only appears at SZAs $>92^{\circ}$. At these SZAs, the absorption due to $\mathrm{OClO}$ along a given line of sight occurs where the local SZA is largest, i.e. near the vertical above the observing point. Thus, a significant part of the $\mathrm{OClO}$ layer is likely to be in the Earth's shadow region where multiply scattered light has a stronger relative impact. This explains why the OClO SCDs are so sensitive to MS in these conditions. The differences between the photochemical behaviours of $\mathrm{BrO}, \mathrm{NO}_{2}$, and $\mathrm{OClO}$ are also manifest from
Fig. 4. BrO SCDs show a sharp decrease above $\sim 92^{\circ}$ SZA (see Fig. 1), consistent with the rapid conversion of $\mathrm{BrO}$ into its night-time reservoirs (mostly $\mathrm{BrCl}$ in the present case) in the absence of sunlight. In contrast, the concentrations of $\mathrm{OClO}$ and $\mathrm{NO}_{2}$ increase with SZA (see Figs. 2 and 3, respectively), which explains the persistence of relatively large SCD values at corresponding SZAs, especially in MS mode. However, $\mathrm{OClO}$ and $\mathrm{NO}_{2}$ SCDs also decrease at very high SZAs. This decrease happens when the mean scattering altitude moves above the trace gas layer. The SZA where the maximum SCD is reached is thus determined by a combination of photochemistry and altitude range of the trace gas layer.

Concerning the comparison of simulated SCDs, the relative differences between the results of the different models and those of IASB arbitrarily taken as reference, appear in the lower plots of Fig. 4 and a summary of the maximum differences found is presented in Table 3. In SS mode, good agreement is obtained below $90^{\circ} \mathrm{SZA}$ between the NIWA, IASB, NILU, and UBRE models: for the three species, the relative difference between the NIWA, NILU, and UBRE models and the IASB one (reference model) is smaller than $1 \%$. However, the SCDs simulated by the ISACCNR model are systematically larger and the relative differences rise up to $4 \%$ for $\mathrm{BrO}, 5 \%$ for $\mathrm{NO}_{2}$ and $7.5 \%$ for OClO. Above $90^{\circ} \mathrm{SZA}$, the agreement between the NIWA, IASB, UBRE, and NILU models is still very good with relative differences smaller than $1.8 \%$ for $\mathrm{BrO}, 1.3 \%$ for $\mathrm{NO}_{2}$, 
$\mathrm{BrO}$
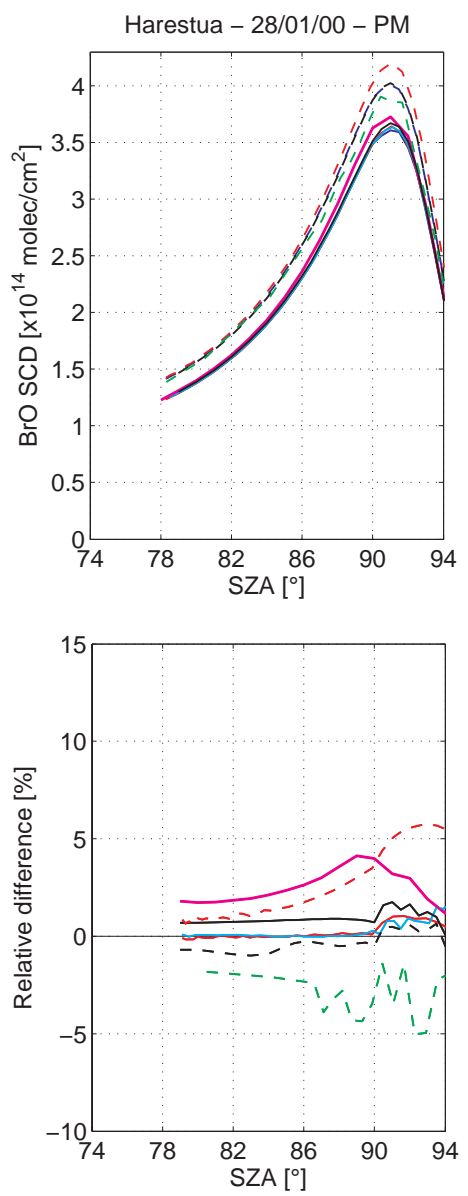

$\mathrm{NO}_{2}$
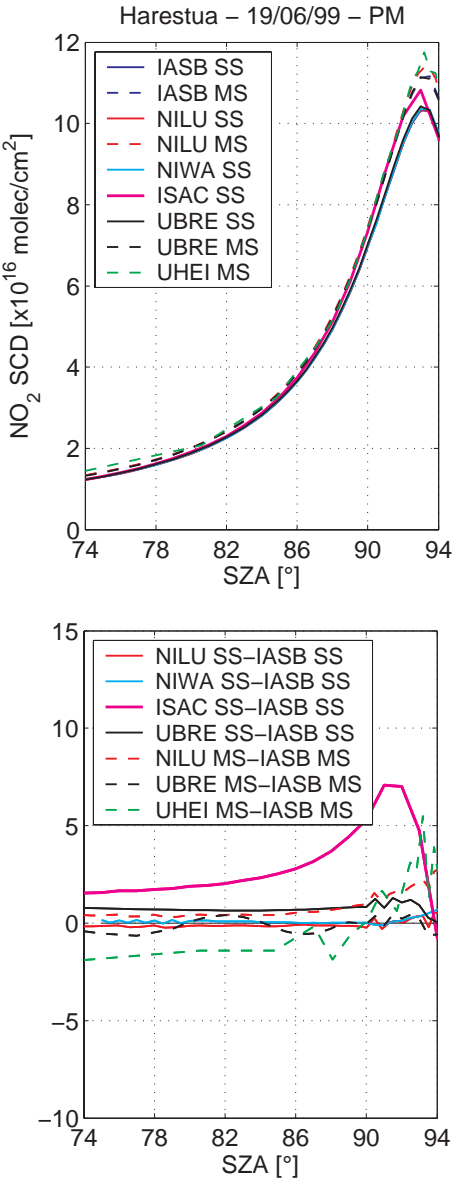

OCIO
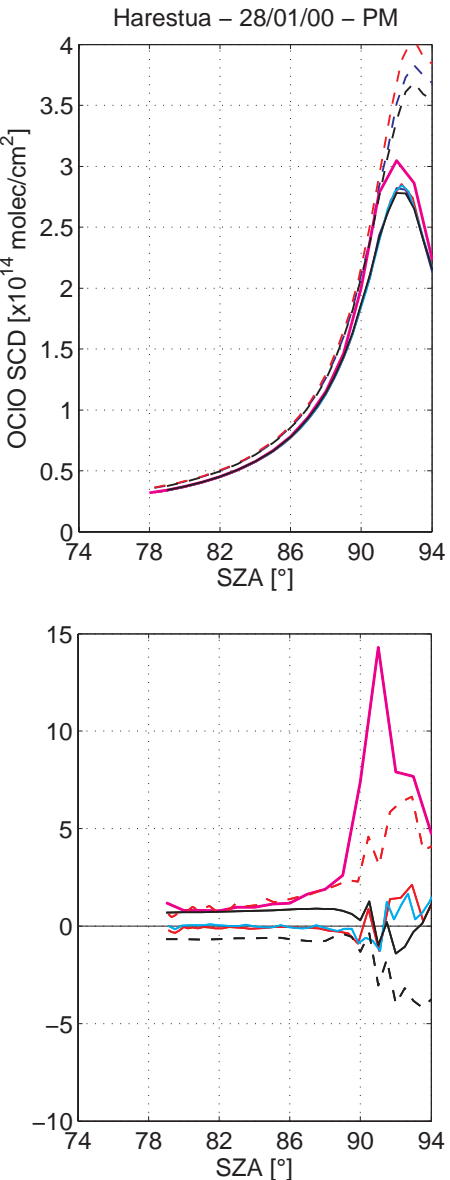

Fig. 4. Sunset $\mathrm{BrO}, \mathrm{NO}_{2}$, and $\mathrm{OClO}$ SCDs calculated in the comparison test in zenith-sky geometry. The upper plots correspond to the SCDs and the lower plots to the relative differences between the results from the different models and those from the IASB model arbitrarily chosen as reference. Solid and dashed lines correspond to calculations in SS and MS modes, respectively. Note that the UHEI OCIO data are missing (see Sect. 3.2) and in the upper plots, the blue, red, and cyan solid lines corresponding to, respectively, the IASB, NILU, and NIWA SCD calculations in SS mode are almost superimposed.

Table 3. Maximum relative differences obtained between the different RT models and the IASB one - arbitrarily taken as reference - for the comparison test in zenith-sky geometry. Note that the SS and MS models have been compared to the IASB model in SS and MS modes, respectively.

\begin{tabular}{lccc}
\hline & $\mathrm{BrO}[\%]$ & $\mathrm{NO}_{2}[\%]$ & $\mathrm{OClO}[\%]$ \\
\hline NILU SS & +1.0 & +0.5 & +2.1 \\
ISAC SS & +4.1 & +7.1 & +14.3 \\
NIWA SS & +1.5 & +0.7 & +1.6 \\
UBRE SS & +1.8 & +1.3 & -1.4 \\
NILU MS & +5.8 & +2.7 & +6.6 \\
UHEI MS & -5.0 & +5.5 & - \\
UBRE MS & -1.0 & -0.6 & -4.2 \\
\hline
\end{tabular}

and $2.1 \%$ for OClO. A maximum spread between models of about $2 \%$ is a better agreement than obtained by Sarkissian et al. (1995) without taking into account photochemical enhancement (from Sarkissian et al. (1995), the maximum spread values rise up to $13 \%$ for $\mathrm{O}_{3}$ and $8 \%$ for $\mathrm{NO}_{2}$ at $\left.94^{\circ} \mathrm{SZA}\right)$. Concerning the ISAC-CNR simulations above $90^{\circ}$ SZA, the discrepancies with the IASB model are larger than for the NIWA and NILU models: the relative differences are smaller than $4 \%$ for $\mathrm{BrO}$ and rise up to $7.1 \%$ for $\mathrm{NO}_{2}$, and $14.3 \%$ for $\mathrm{OClO}$. Although these maximum relative differences are consistent with those of Sarkissian et al. (1995), they suggest that the ISAC-CNR model differs from the other models in the way the optical thickness of each atmospheric shell is calculated. Sarkissian et al. (1995) investigated the influence of the different methods used to interpolate the concentration and to calculate the geometrical path in individual shells. They found that the impact of these parameters 
increases with increasing SZA and can reach $4 \%$ above $90^{\circ}$ SZA. Since photochemical enhancement is included in the present test, we cannot neglect the impact of differences in interpolating the tables of photochemical species concentrations. This effect is consistent with the increase in the relative differences between the models with increasing SZA since the step between the SZA values corresponding to the concentration tables is increasing at large SZAs, due to the fact that the stacked box photochemical model PSCBOX provides output with a constant time step. Concerning the calculations in MS mode, the agreement below $90^{\circ} \mathrm{SZA}$ between the NILU, IASB, UBRE, and UHEI models is good since the relative differences with the IASB model results are smaller than $4.4 \%$. Above $90^{\circ} \mathrm{SZA}$, slightly larger discrepancies are generally found, as in SS mode, and the maximum relative differences with the IASB model results rise up to $6.6 \%$ for the NILU model (obtained for OCIO SCD calculations), $5.5 \%$ for the UHEI model (obtained for $\mathrm{NO}_{2}$ SCD calculations), and $4.2 \%$ for the UBRE model (obtained for OClO SCD calculations). It should be noted that UHEI $\mathrm{OClO}$ data are absent from the comparison. This is caused by the fact that too many photons (around $10^{5}$ ) would have been required to calculate each SCD with sufficient accuracy and precision. In contrast to the $\mathrm{NO}_{2}$ or $\mathrm{BrO}$ profile, stratospheric $\mathrm{OClO}$ is usually confined to a layer of only a few kilometres thickness, and the concentration gradient is very high at its lower and upper ends (see Fig. 2). The Monte Carlo nature of the UHEI model causes statistical fluctuations (from photon path to photon path) of the altitude of the first scattering event the photon encounters after atmosphere entry. If this event occurs above the OClO layer, then the path through this layer is short. If the event occurs within the $\mathrm{OClO}$ layer, the light path through this layer is long. If the event occurs below the OClO layer, then the path through the layer has also been long, though shorter than in the second case. Accordingly, small variations in the altitude of the first scattering event, arising from statistical fluctuations, lead to large variations in path length and hence to large fluctuations in the simulated SCD. This noise can only be reduced with a very large number of modelled photons, which causes the UHEI model to be inefficient for this specific kind of scenario. With the expected increase in computational power, this disadvantage is likely to become less significant in the near future.

\section{Multi-axis simulations of $\mathrm{NO}_{2}$ and HCHO SCDs}

\subsection{Comparison test description}

In contrast to the zenith-sky simulations, photochemical enhancement has not been taken into account in the MAX simulations. The reason is that this effect becomes significant only during twilight, i.e. above $85^{\circ} \mathrm{SZA}$, and we have limited our comparison to the $38^{\circ}-85^{\circ} \mathrm{SZA}$ range because the sen- sitivity of the MAX-DOAS observations to the troposphere is largest during daytime, i.e. at small SZA. The $\mathrm{NO}_{2}$ and $\mathrm{HCHO}$ profiles used for the initialization of the models are shown in Fig. 5. All calculations included absorption by $\mathrm{O}_{3}$ and in case of $\mathrm{HCHO}$, also absorption by $\mathrm{NO}_{2}$. SCD simulations have been performed for $5^{\circ}, 10^{\circ}$, and $20^{\circ}$ elevation above the horizon. For each elevation angle, four values of the azimuth angle of line of sight (AzLOS) have been considered: $30^{\circ}, 60^{\circ}, 90^{\circ}$, and $120^{\circ}$. The AzLOS is the relative azimuth angle between the pointing direction of the instrument and the sun azimuth. The other settings are shown in Table 4. Concerning the HCHO SCD calculations, the layer thickness in the altitude range where the concentration of this species changes rapidly with altitude $(0-3 \mathrm{~km})$ has been fixed to $0.2 \mathrm{~km}$ instead of the $1 \mathrm{~km}$ thickness used in case of $\mathrm{NO}_{2}$, reducing interpolation effects. Only models enabling calculations in MS mode have been involved in this test since MS is the only acceptable scattering mode in MAX geometry (Wittrock et al., 2004). These models are: IASB, NILU, UBRE and UHEI.

\subsection{Results}

Figure 6 shows the results of the $\mathrm{NO}_{2}$ and HCHO SCD simulations for $5^{\circ}, 10^{\circ}$, and $20^{\circ}$ elevation and $90^{\circ}$ AzLOS. A summary of the maximum differences between the different models and the IASB one (again taken arbitrarily as reference model) is also presented in Table 5. The agreement between IASB, NILU, UBRE and UHEI is good: when comparing the results for both species over the whole SZA range and for all the elevation angles, the relative differences between the NILU, UBRE, and UHEI models and the IASB one are smaller than $5.1 \%$. Concerning the UBRE model, it underestimates the IASB model results by at most $4.5 \%$ for $\mathrm{NO}_{2}$ and $5.1 \%$ for $\mathrm{HCHO}$. Furthermore, the relative differences are also almost constant over the whole SZA range. This is in contrast to the relative differences between the UHEI and IASB models which show a SZA dependence, especially at low elevation angles: e.g., for $\mathrm{NO}_{2}$ at $5^{\circ}$ elevation, the UHEI model results overestimate the IASB ones by $3 \%$ at $40^{\circ} \mathrm{SZA}$ and underestimate them by $3.6 \%$ at $85^{\circ}$ SZA. However, with maximum relative differences of $3.8 \%$ for $\mathrm{NO}_{2}$ and $4.5 \%$ for $\mathrm{HCHO}$ (see Table 5), the agreement between both models is good. As expected since they are both based on the UVspec/DISORT package, the NILU and the IASB models agree very well: for both $\mathrm{NO}_{2}$ and $\mathrm{HCHO}$, the relative difference between the results of both models is smaller than $1.3 \%$ over the entire SZA range and for all elevation angles.

The impact of the relative azimuth has been tested by calculating $\mathrm{NO}_{2}$ and $\mathrm{HCHO}$ SCDs for different AzLOS values $\left(30^{\circ}, 60^{\circ}, 90^{\circ}\right.$, and $\left.120^{\circ}\right)$. The AzLOS effect on $\mathrm{NO}_{2} \mathrm{SCDs}$ is illustrated in Fig. 7 where the relative differences between the $\mathrm{NO}_{2}$ SCDs at $30^{\circ}, 60^{\circ}$, and $120^{\circ}$ AzLOS and the SCD at $90^{\circ}$ AzLOS (reference) are plotted as a function of SZA 

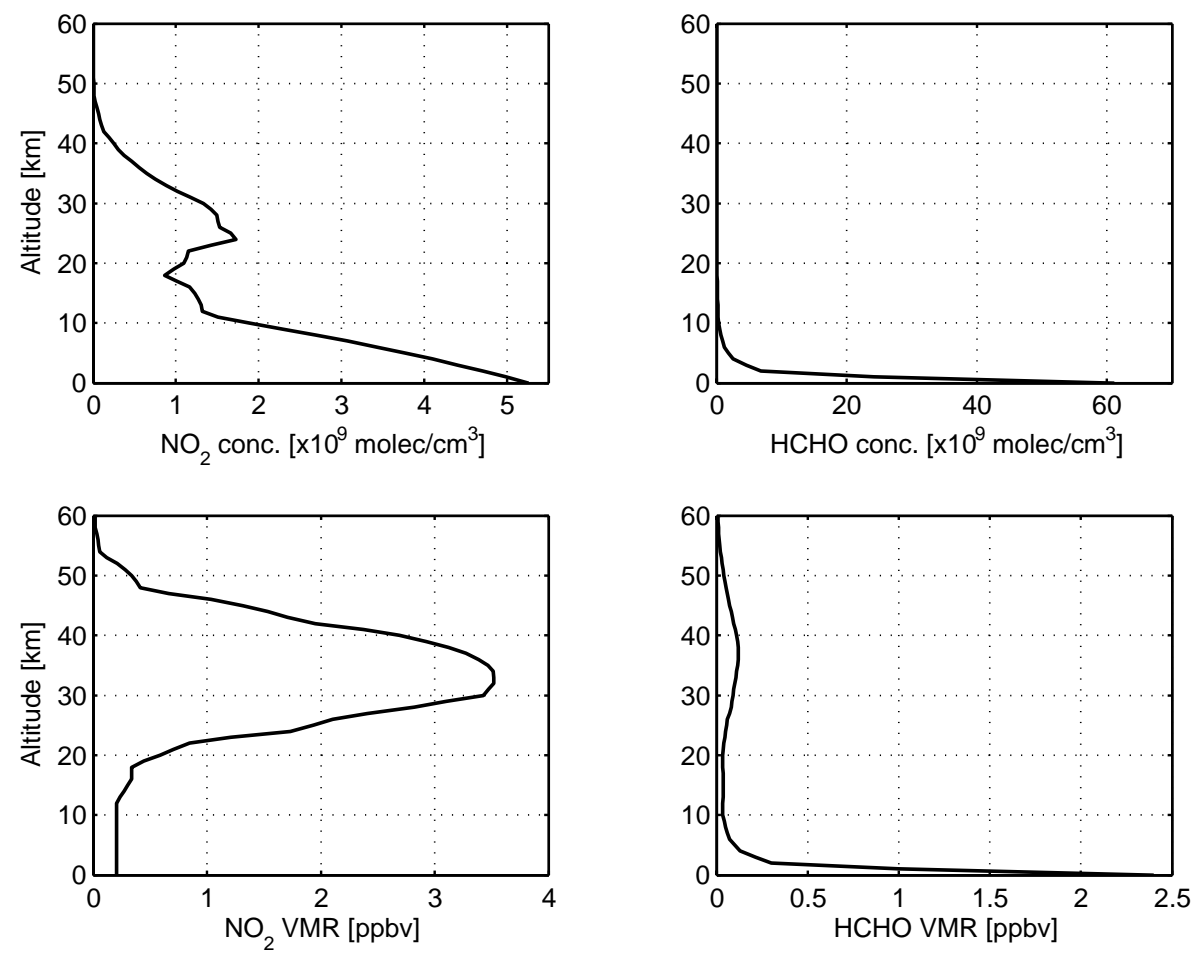

Fig. 5. $\mathrm{NO}_{2}$ (left) and $\mathrm{HCHO}$ (right) profiles in concentration (upper plots) and VMR (lower plots) used to initialize the RT models in the comparison tests in MAX geometry.

Table 4. Model settings for the comparison test in MAX geometry. It should be noted that the same settings are used for the tests on aerosols effect (except Mie scattering is then included; see Sect. 5) and ground albedo effect (with the ground albedo value then fixed to 0 and 0.9 instead of 0.2; see Sect. 6). All the initialization data are available on the QUILT web site (http://nadir.nilu.no/quilt/).

\begin{tabular}{|c|c|}
\hline Altitude grid & $\begin{array}{l}\mathrm{NO}_{2}: 0-120 \mathrm{~km} / 1 \mathrm{~km} \text { thick } \\
\mathrm{HCHO}: 0-120 \mathrm{~km} / 0.2 \mathrm{~km} \text { thick between } \\
0 \text { and } 3 \mathrm{~km} \text { and } 1 \mathrm{~km} \text { thick above } 3 \mathrm{~km}\end{array}$ \\
\hline Wavelength & $\begin{array}{l}356 \mathrm{~nm}(\mathrm{HCHO}) \\
422 \mathrm{~nm}\left(\mathrm{NO}_{2}\right)\end{array}$ \\
\hline $\mathrm{p}, \mathrm{T}$ profiles & $\begin{array}{l}\text { From SLIMCAT 3-D-CTM; interpolation using } \\
\text { AFGL } 1976 \text { outside the SLIMCAT altitude range }\end{array}$ \\
\hline $\mathrm{O}_{3}$ profile & $\begin{array}{l}\text { From PSCBOX model; interpolation using } \\
\text { AFGL } 1976 \text { outside the SLIMCAT altitude range }\end{array}$ \\
\hline $\mathrm{NO}_{2}$ profile (for $\mathrm{HCHO} \mathrm{SCD}$ calculations) & $\begin{array}{l}\text { From PSCBOX model; interpolation using } \\
\text { AFGL } 1976 \text { outside the SLIMCAT altitude range }\end{array}$ \\
\hline $\mathrm{HCHO}$ and $\mathrm{NO}_{2}$ profiles (see Fig. 5) & $\begin{array}{l}\text { HCHO: Barbe et al. (1979); } \\
\text { Ehhalt and Tönnißen (1979) } \\
\mathrm{NO}_{2}: \text { from PSCBOX model }\end{array}$ \\
\hline Mie scattering & Not included \\
\hline Refraction & Not included \\
\hline Cross sections sets & $\begin{array}{l}\text { HCHO: Cantrell et al. (1990) } \\
\mathrm{NO}_{2} \text { : Burrows et al. (1998) } \\
\mathrm{O}_{3} \text { : Burrows et al. (1999) }\end{array}$ \\
\hline Ground albedo & 0.20 \\
\hline Elevation angle & $5^{\circ}, 10^{\circ}$, and $20^{\circ}$ \\
\hline Azimuth angle of line of sight & $30^{\circ}, 60^{\circ}, 90^{\circ}$, and $120^{\circ}$ \\
\hline Scattering mode & MS \\
\hline
\end{tabular}



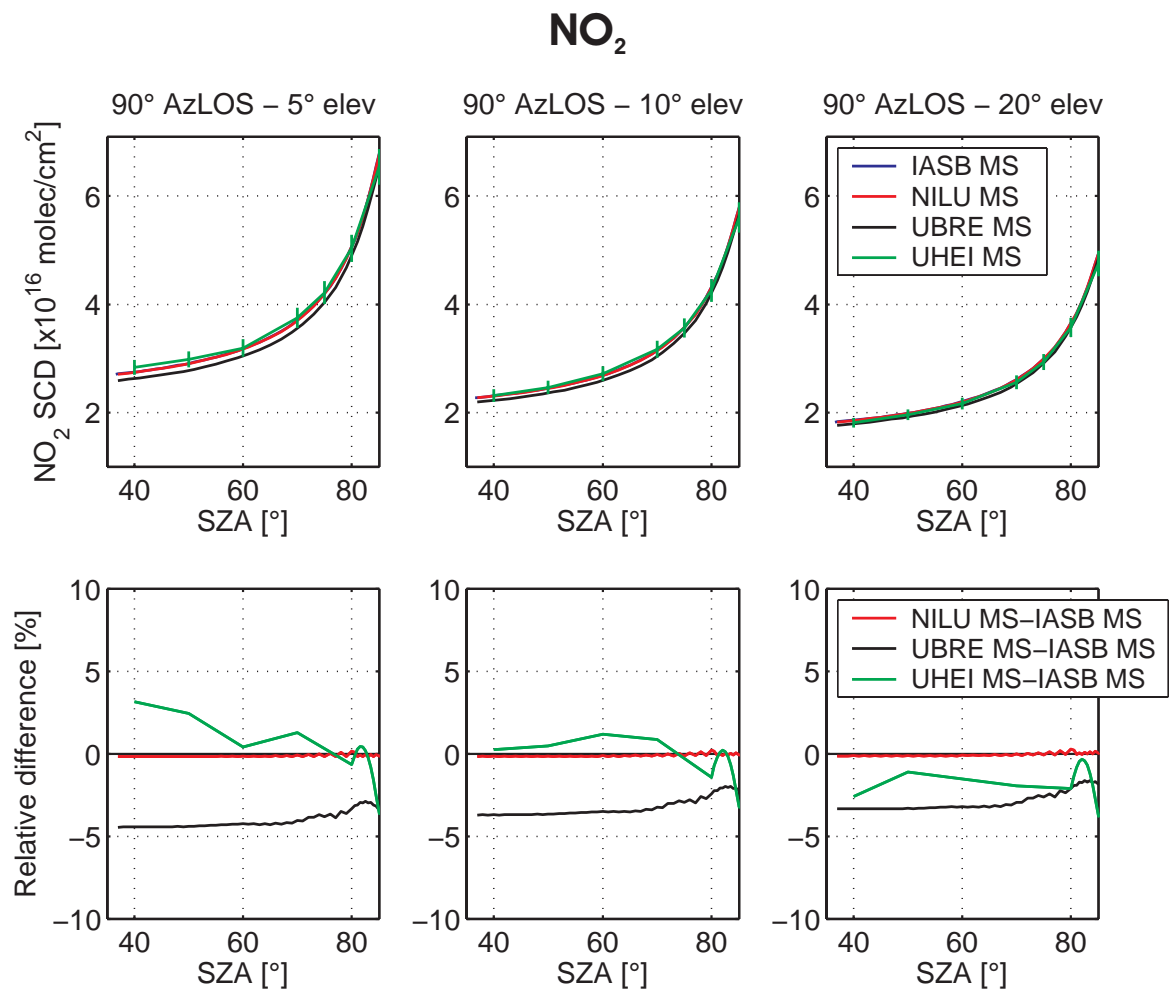

$\mathrm{HCHO}$
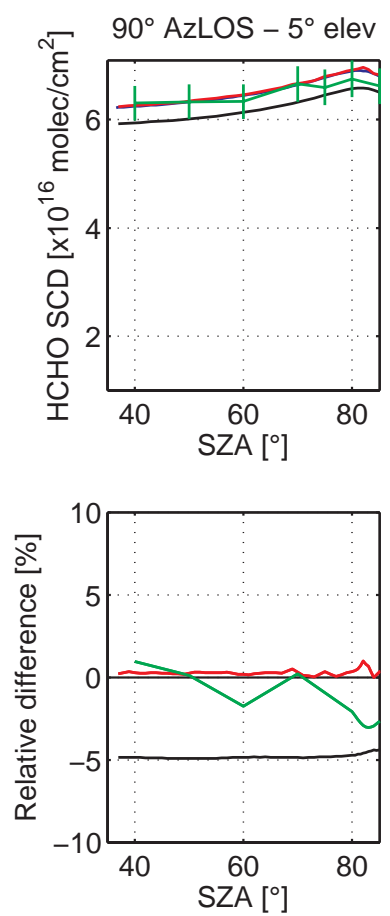

$90^{\circ}$ AzLOS - $10^{\circ}$ elev
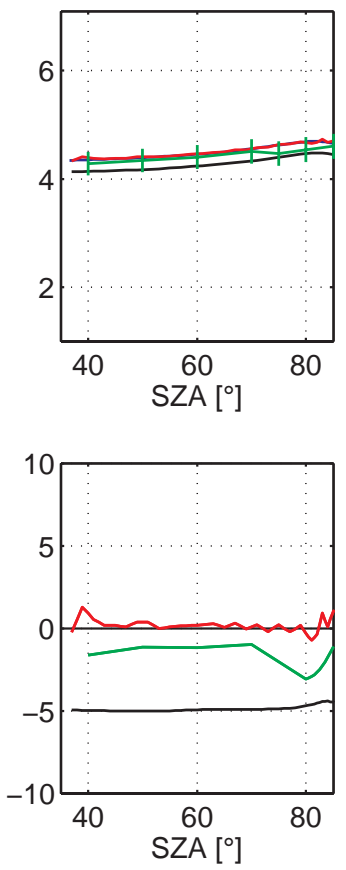

$90^{\circ}$ AzLOS $-20^{\circ}$ elev
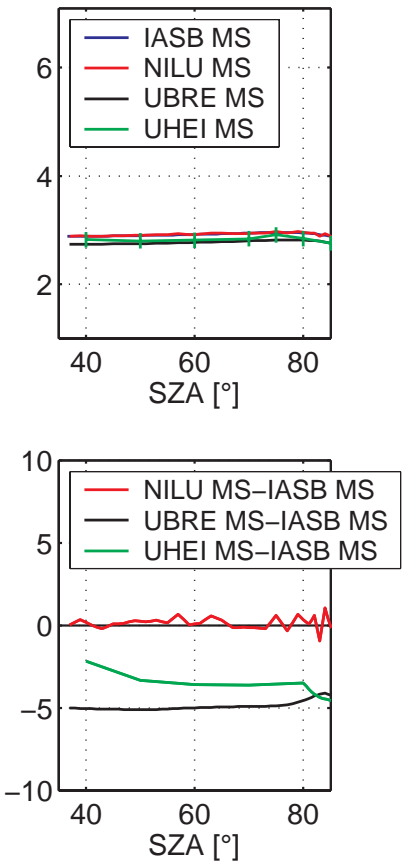

Fig. 6. $\mathrm{NO}_{2}$ and $\mathrm{HCHO} S \mathrm{SCD}$ calculated in MS mode in the comparison test in MAX geometry. For each species, the upper plots correspond to the SCDs and the lower plots to the relative differences between the different models and the IASB one arbitrarily chosen as reference. Results for $90^{\circ}$ AzLOS and for $5^{\circ}, 10^{\circ}$, and $20^{\circ}$ elevation are plotted here. 
Table 5. Maximum relative differences obtained between the different RT models and the IASB one - arbitrarily taken as reference - for the comparison test in MAX geometry.

\begin{tabular}{|c|c|c|c|c|}
\hline & & $5^{\circ}$ elevation $[\%]$ & $10^{\circ}$ elevation $[\%]$ & $20^{\circ}$ elevation $[\%]$ \\
\hline \multirow{2}{*}{ NILU MS } & $\mathrm{NO}_{2}$ & -0.2 & +0.2 & +0.3 \\
\hline & $\mathrm{HCHO}$ & +1.0 & +1.3 & +1.1 \\
\hline \multirow{2}{*}{ UHEI MS } & $\mathrm{NO}_{2}$ & -3.6 & -3.2 & -3.8 \\
\hline & $\mathrm{HCHO}$ & -3.0 & -3.0 & -4.5 \\
\hline \multirow{2}{*}{ UBRE MS } & $\mathrm{NO}_{2}$ & -4.5 & -3.7 & -3.3 \\
\hline & $\mathrm{HCHO}$ & -5.0 & -5.0 & -5.1 \\
\hline
\end{tabular}

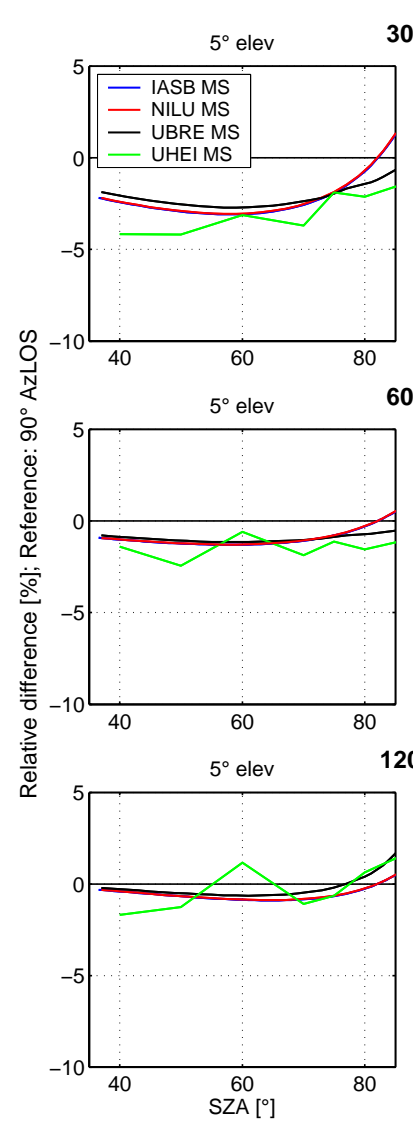

$30^{\circ}$ AzLOS

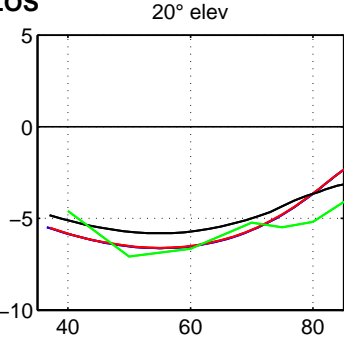

$60^{\circ}$ AzLOS

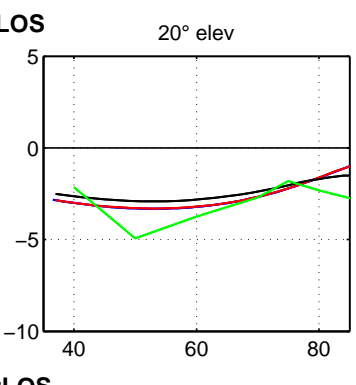

$120^{\circ}$ AzLOS

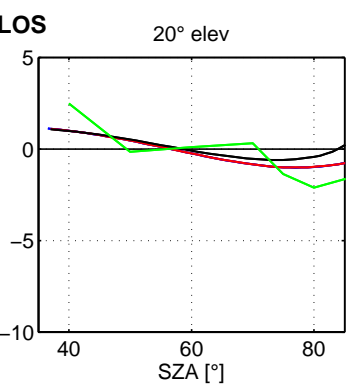

Fig. 7. Impact of the relative azimuth on the $\mathrm{NO}_{2} \mathrm{SCDs}$ calculated in MAX geometry. The relative differences between the $\mathrm{NO}_{2} \mathrm{SCDs}$ calculated at $30^{\circ}$ (upper plots), $60^{\circ}$ (middle plots), and $120^{\circ}$ (lower plots) AzLOS and those calculated at $90^{\circ}$ AzLOS (reference case) are plotted here. Left and right plots correspond to results for $5^{\circ}$ and $20^{\circ}$ elevation, respectively. Note that the IASB blue lines are superimposed to the NILU red lines.

for $5^{\circ}$ and $20^{\circ}$ elevation. The largest AzLOS impact on $\mathrm{NO}_{2}$ SCDs $(7 \%)$ occurs at $50^{\circ} \mathrm{SZA}$ for $30^{\circ}$ AzLOS and $20^{\circ}$ elevation, i.e. at small AzLOS and high elevation angle. In case of HCHO (not shown here), the AzLOS effect is smaller by 1-2\% compared to $\mathrm{NO}_{2}$. It should be noted that a larger rel- ative azimuth effect is expected in presence of aerosols, due to the strong preference of forward scattering by particles, whereas the Rayleigh phase function is symmetric in forward and backward directions. Concerning the consistency between the IASB, NILU, UBRE, and UHEI models with respect to the impact of the AzLOS, Fig. 7 shows that they agree reasonably well.

\section{Impact of aerosol scattering on multi-axis simulations of $\mathrm{NO}_{2}$ and HCHO SCDs}

Aerosols have a strong impact on MAX-DOAS observations (Wagner et al., 2004; Wittrock et al., 2004; and Heckel et al., 2005). The most important effect of the aerosol extinction is a reduction of the visibility of the atmosphere and thus a limitation by scattering of the light path of the lowest viewing directions, reducing the difference in tropospheric absorption path between the viewing directions. It has been shown by Wagner et al. (2004) that the impact of aerosols on $\mathrm{O}_{4}$ SCDs can provide a new method to derive information on atmospheric aerosols.

In the present study, $\mathrm{MAX} \mathrm{NO}_{2}$ and $\mathrm{HCHO} \mathrm{SCDs}$ have been simulated with and without aerosol scattering in order to test the consistency between the different RT models regarding the impact of aerosols in this geometry. The aerosol settings are shown in Fig. 8 (profiles of the extinction and absorption coefficients) and Table 6 (asymmetry factor). They have been constructed from the aerosol model of Shettle (1989) included in the IASB and NILU RT models using a surface visibility of $100 \mathrm{~km}$. The settings in the boundary layer and troposphere correspond to mixture of water soluble and dust-like aerosols representative of a rural environment (low aerosol content). In the stratosphere, sulphuric acid aerosol settings corresponding to summer background conditions have been used. The other initialization parameters are the same as described in Sect. 4.1, except that HCHO and $\mathrm{NO}_{2} \mathrm{SCDs}$ have been calculated only for $90^{\circ}$ AzLOS.

Figure 9 shows MAX $\mathrm{NO}_{2}$ and $\mathrm{HCHO}$ SCDs simulated with and without aerosol scattering. Qualitatively, the impact of aerosols is the same for all models: a decrease of $\mathrm{NO}_{2}$ and HCHO SCDs occurs when aerosol scattering is included 

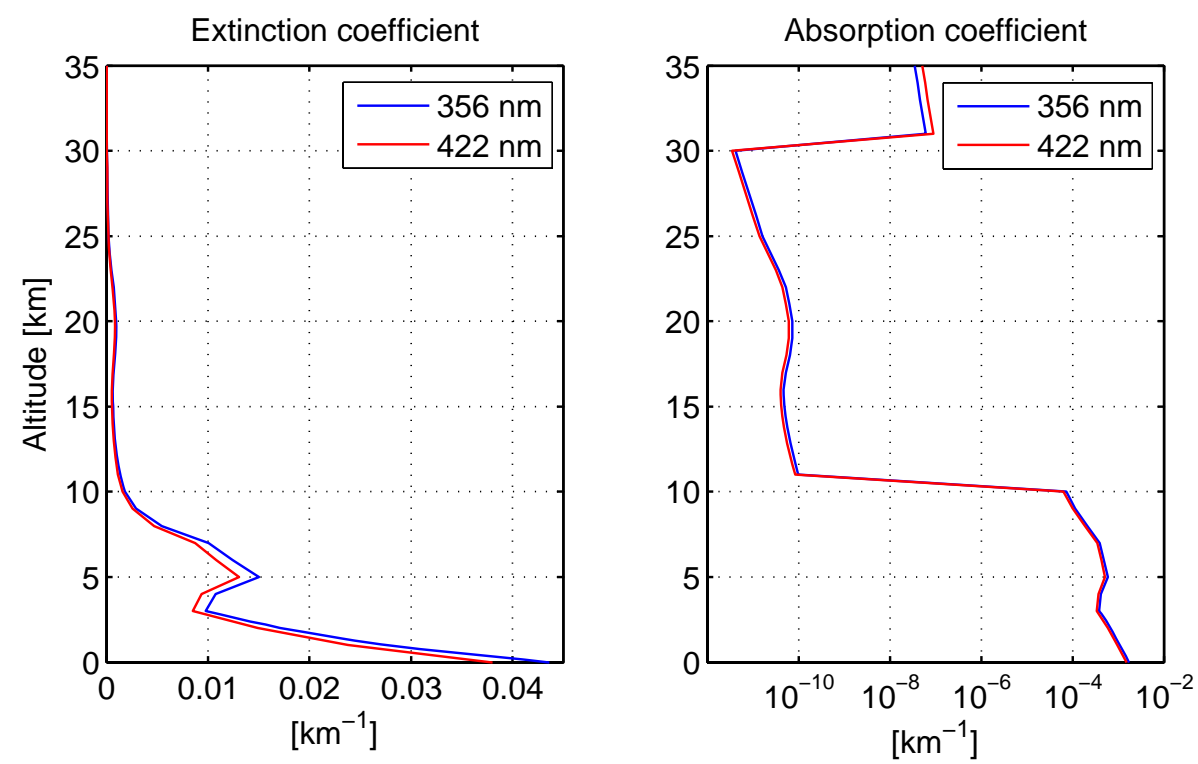

Fig. 8. Profiles of the aerosol extinction (left) and absorption (right) coefficients used for testing the impact of aerosols on MAX simulations of $\mathrm{HCHO}(356 \mathrm{~nm})$ and $\mathrm{NO}_{2}(422 \mathrm{~nm}) \mathrm{SCDs}$, respectively.

in the calculations. The presence of aerosols leads to a reduction of the direct light path, especially in the lowest layers, and therefore the absorption by $\mathrm{NO}_{2}$ and $\mathrm{HCHO}$ is reduced (Wagner et al., 2004). The impact of aerosol scattering also decreases at higher elevation angles, due to the fact that, as the elevation angle increases, the mean scattering height increases and therefore the MAX SCD simulations become less sensitive to the lowest layers where the aerosol effect is largest.

When SCDs calculated with aerosols are compared, the different models agree reasonably well: they differ by $9 \%$ at most, which is of the same order of magnitude as the differences found for calculations without aerosols $(5 \%$, see Sect. 4.2). However, regarding the quantitative impact of the aerosol scattering, expressed in Fig. 9 by the relative differences between simulations with and without aerosol scattering, the models differ significantly. For example, in $\mathrm{HCHO}$ SCD simulations at $5^{\circ}$ elevation, an aerosol impact of about $10 \%$ is found with the UHEI and UBRE models, which is twice as much as the impact obtained with the NILU and IASB models. In case of $\mathrm{NO}_{2}$, such a difference is found between the UBRE and UHEI model results (see results for $5^{\circ}$ elevation in Fig. 9). Figure 9 also shows that the impact of aerosol scattering is larger on $\mathrm{NO}_{2}$ than on HCHO SCDs: the relative differences between calculations with and without aerosol scattering range for all models, elevation angles, and SZAs between $-21 \%$ and $+4 \%$ for $\mathrm{NO}_{2}$ and between $-13 \%$ and $+1.5 \%$ for $\mathrm{HCHO}$. These discrepancies obtained between the different models could not be resolved satisfactorily so far. It may be related to the different approximations used in the models for resolving the RT equation. For exam-
Table 6. Profiles of asymmetry factor used for testing the impact of aerosols on MAX simulations of $\mathrm{HCHO}(356 \mathrm{~nm})$ and $\mathrm{NO}_{2}$ (422 nm) SCDs.

\begin{tabular}{lcc}
\hline & $\begin{array}{c}\text { Asymmetry factor } \\
356 \mathrm{~nm}\end{array}$ & $\begin{array}{c}\text { Asymmetry factor } \\
422 \mathrm{~nm}\end{array}$ \\
\hline $0-10 \mathrm{~km}$ & 0.661 & 0.652 \\
$11-30 \mathrm{~km}$ & 0.698 & 0.693 \\
$>30 \mathrm{~km}$ & 0.701 & 0.698 \\
\hline
\end{tabular}

ple, the UBRE and UHEI models are spherical whereas the NILU and IASB models use the pseudo-spherical approximation. A Fourier expansion is also applied in the NILU and IASB models, which could lead to a lose of angular information if too few Fourier terms are considered. In order to progress further in our understanding of the persistent discrepancies regarding the aerosol impact, a thorough examination of individual aerosol routines and additional comparison tests appear to be needed, which is beyond the scope of the present intercomparison exercise. This issue, and more generally the impact of aerosol scattering on MAX DOAS AMF simulations, is addressed more thoroughly as part of a new exercise, currently led by the University of Heidelberg in the framework of the European Network of Excellence on Atmospheric Composition Change ACCENT. More details on this new exercise as well as preliminary results can be found on the following web page: http://satellite.iup. uni-heidelberg.de/index.php/RTM_Workshop/149/0/. 
$\mathrm{NO}_{2}$
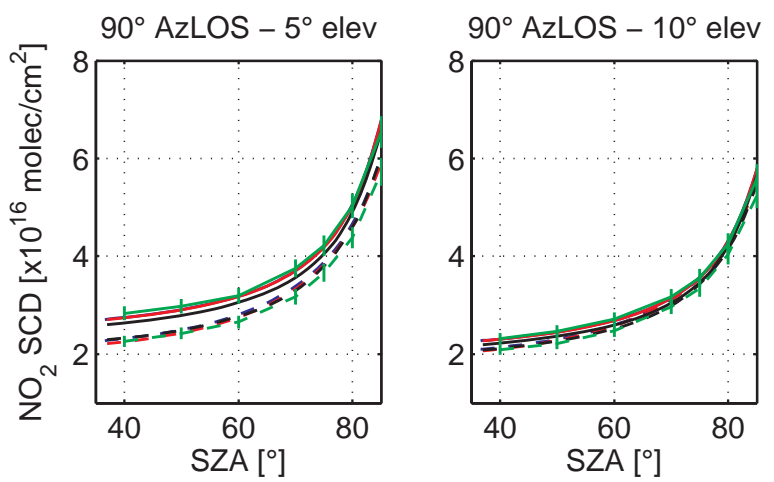

$90^{\circ}$ AzLOS $-20^{\circ}$ elev
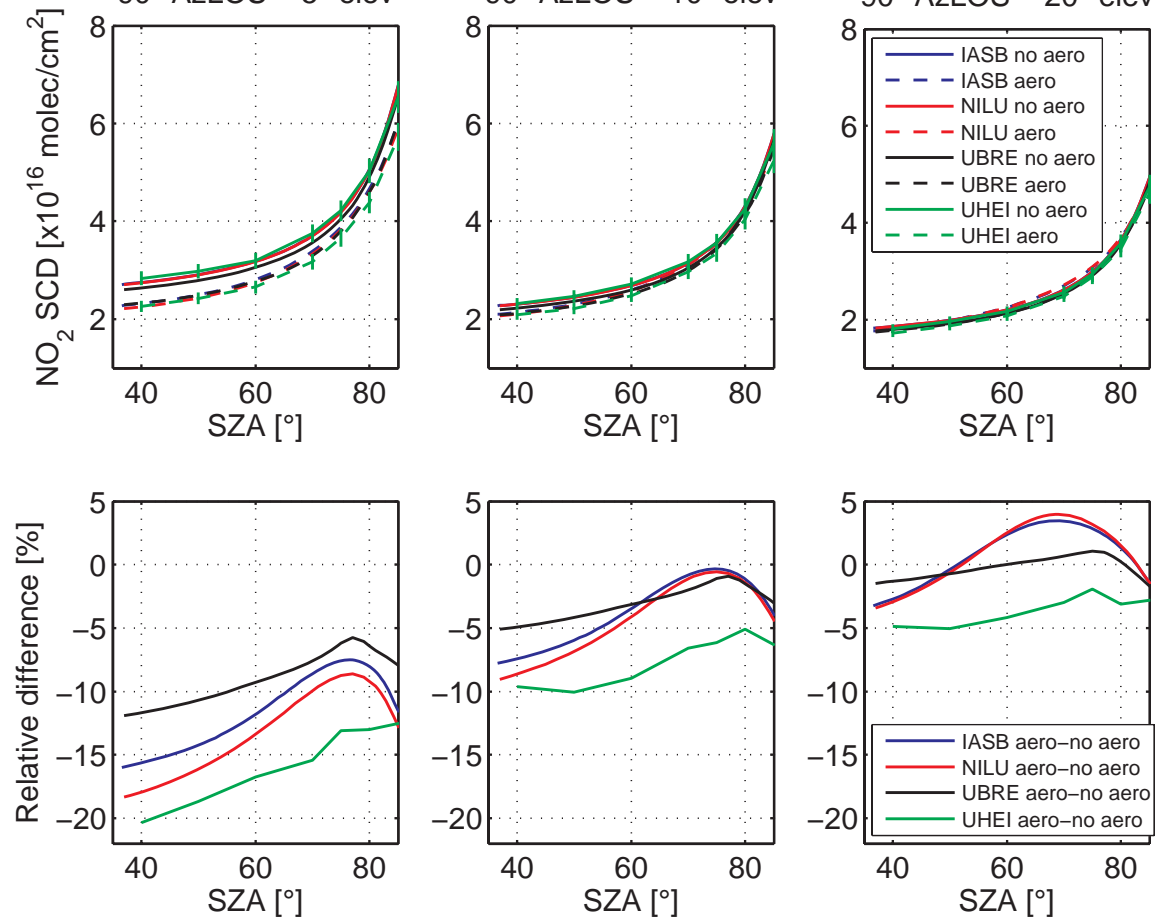

$\mathrm{HCHO}$
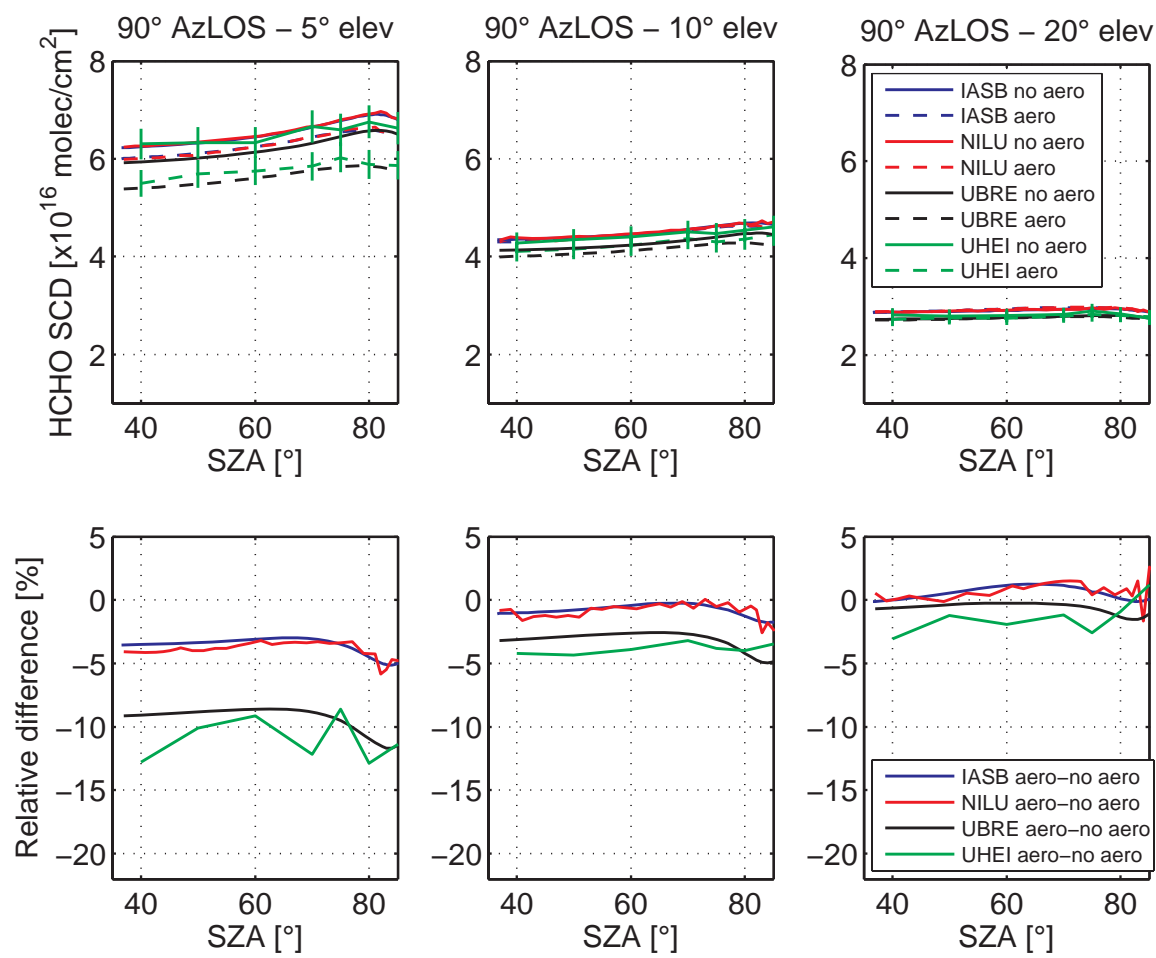

Fig. 9. Impact of aerosol scattering on simulated $\mathrm{MAX} \mathrm{NO}$ and HCHO SCDs. For each species, the upper plots correspond to the SCDs and the lower plots to the relative differences between SCDs calculated with and without aerosol scattering (reference: without aerosol scattering). Results for $90^{\circ}$ AzLOS and for $5^{\circ}, 10^{\circ}$, and $20^{\circ}$ elevation are plotted here. 


\section{Impact of ground albedo on multi-axis simulations of $\mathrm{NO}_{2}$ and HCHO SCDs}

Ground albedo has a significant impact on the radiative transfer close to the ground (Hönninger et al., 2004; Wittrock et al., 2004). It is particularly important to properly estimate this parameter for observational sites displaying large albedo changes depending on the season or viewing direction. The main effect of an increase of the albedo is an increase of the number of scattering events in the layers close to the surface, resulting in longer absorption paths at these altitudes and therefore in higher absolute AMFs. However, the difference in AMF between off-axis and zenith-sky viewing directions is reduced, owing to the fact that the enhancement of the optical path with increasing albedo is largest for zenithsky observations (Wittrock et al., 2004).

In order to test the consistency between the different RT models regarding the impact of the ground albedo in MAX geometry, $\mathrm{NO}_{2}$ and $\mathrm{HCHO}$ SCDs have been simulated with ground albedo values fixed to 0 and 0.9 . The other model settings are the same as those described in Sect. 4.1. As for the test on the impact of aerosol scattering, simulations have been performed only for $90^{\circ}$ AzLOS.

Figure 10 illustrates the ground albedo effect on simulated MAX HCHO and $\mathrm{NO}_{2}$ SCDs. The UBRE, NILU, and IASB models show excellent consistency with similar HCHO and $\mathrm{NO}_{2}$ SCD increases being obtained with the three models. An increase in surface albedo value from 0.0 to 0.9 leads to an increase of the HCHO SCD of about $20 \%$ and $55 \%$ at $80^{\circ} \mathrm{SZA}$ for $5^{\circ}$ and $20^{\circ}$ elevation, respectively, whereas the $\mathrm{NO}_{2}$ SCD increases by $5 \%$ and $12 \%$ under the same conditions. The fact that the HCHO SCDs is more sensitive to the ground albedo is expected since for the present simulations, $\mathrm{HCHO}$, in contrast to $\mathrm{NO}_{2}$, is mostly located in the lower part of the troposphere (between 0 and $5 \mathrm{~km}$ ). In case of the UHEI model, the SCDs simulated for a surface albedo value of 0.0 agree reasonably well with the results from the other models. This agreement is similar to the one obtained for medium (0.2) surface albedo conditions (see Sect. 4). For very high surface albedo (0.9), the UHEI model gives generally larger SCD values, especially above $70^{\circ} \mathrm{SZA}$. However, in case of HCHO SCDs, the differences between the UHEI model results and the analytical models results are similar to the differences found between the SCDs calculated by the three analytical models. Due to the larger SCD values obtained when surface albedo is fixed to 0.9, the UHEI model gives a significantly larger relative increase in SCDs compared to the other models: when the surface albedo increases from 0.0 to 0.9 , the $\mathrm{SCD}$ increases at $80^{\circ} \mathrm{SZA}$ for $5^{\circ}$ and $20^{\circ}$ elevation reach $32 \%$ and $84 \%$ for $\mathrm{HCHO}$, and $12 \%$ and $35 \%$ for $\mathrm{NO}_{2}$. This behaviour could be related to the fact that the modelling of the absolute radiance still poses a challenge to backward Monte Carlo approaches, which is also under investigation by other groups. At high albedo, light reflected off the ground is unattenuated and increases the signal of ab- sorbers near the ground, so the absolute radiance begins to play a significant role in the SCD calculations. The present intercomparison exercise was aimed at detecting those subtle effects, and the results will help to optimize the modelling. So will comparison with measurements, e.g., as performed in Weidner et al. (2005).

\section{Conclusions}

In the present intercomparison exercise, we have tested the consistency between six RT models used for interpreting ground-based zenith-sky and MAX-DOAS observations in the QUILT EU project. In the context of this project based on the exploitation of the NDSC, the comparison and optimization of these RT models is of central importance in order to provide accurate time-series of ground-based DOAS observations. This study represents a step forward with respect to previously published work in that it compares RT models in MAX geometry and takes into account photochemical enhancement effect for calculating SCDs of rapidly photolysing species in zenith-sky geometry.

Comparisons of $\mathrm{NO}_{2}$ and HCHO SCDs in MAX geometry and multiple scattering mode without aerosol scattering show good agreement between all involved models: the calculated $\mathrm{NO}_{2}$ and HCHO SCDs differ generally by no more than 5\% in the SZA and elevation angle ranges investigated $\left(35^{\circ}-85^{\circ}\right.$ and $5^{\circ}-20^{\circ}$, respectively). The impacts of the relative azimuth, aerosol scattering, and ground albedo on $\mathrm{NO}_{2}$ and HCHO SCDs have been also quantitatively determined. The azimuth effect is found to be the largest at small AzLOS and high elevation angles. The maximum differences relative to $90^{\circ}$ AzLOS in the $30^{\circ}-120^{\circ}$ AzLOS range and for $20^{\circ}$ elevation rising up to $7 \%$ and $5 \%$ for $\mathrm{NO}_{2}$ and HCHO SCDs, respectively. The models have also shown reasonably good consistency concerning this effect. This is in contrast to the aerosol scattering effect for which significant discrepancies still persist. Since all codes have been initialized identically, this result suggests that significant differences exist between the models regarding the treatment of aerosol scattering, may be related to the different approximations used for resolving the RT equation. This issue, and more generally the impact of aerosol scattering on the MAX DOAS AMF simulations, is addressed more thoroughly as part of a new intercomparison exercise, currently led by the University of Heidelberg in the framework of the European Network of Excellence ACCENT. More details on this new exercise as well as preliminary results can be found on the following web page: http://satellite.iup. uni-heidelberg.de/index.php/RTM_Workshop/149/0/. In the test on the impact of the ground albedo, very good agreement has been achieved between the IASB, NILU, and UBRE models whereas the albedo effect is significantly larger using the UHEI model, which is based on a Monte Carlo approach. It should be noted that the conclusions drawn here on the 
$\mathrm{NO}_{2}$
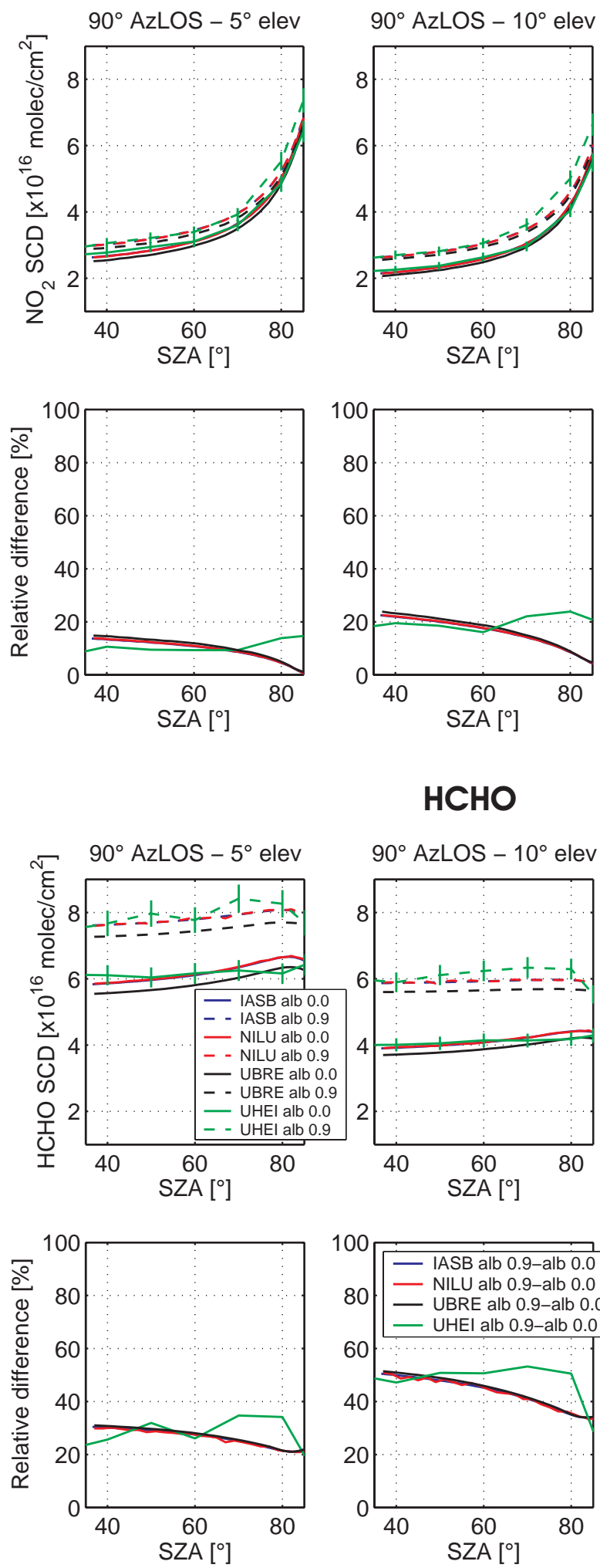

$\mathrm{HCHO}$
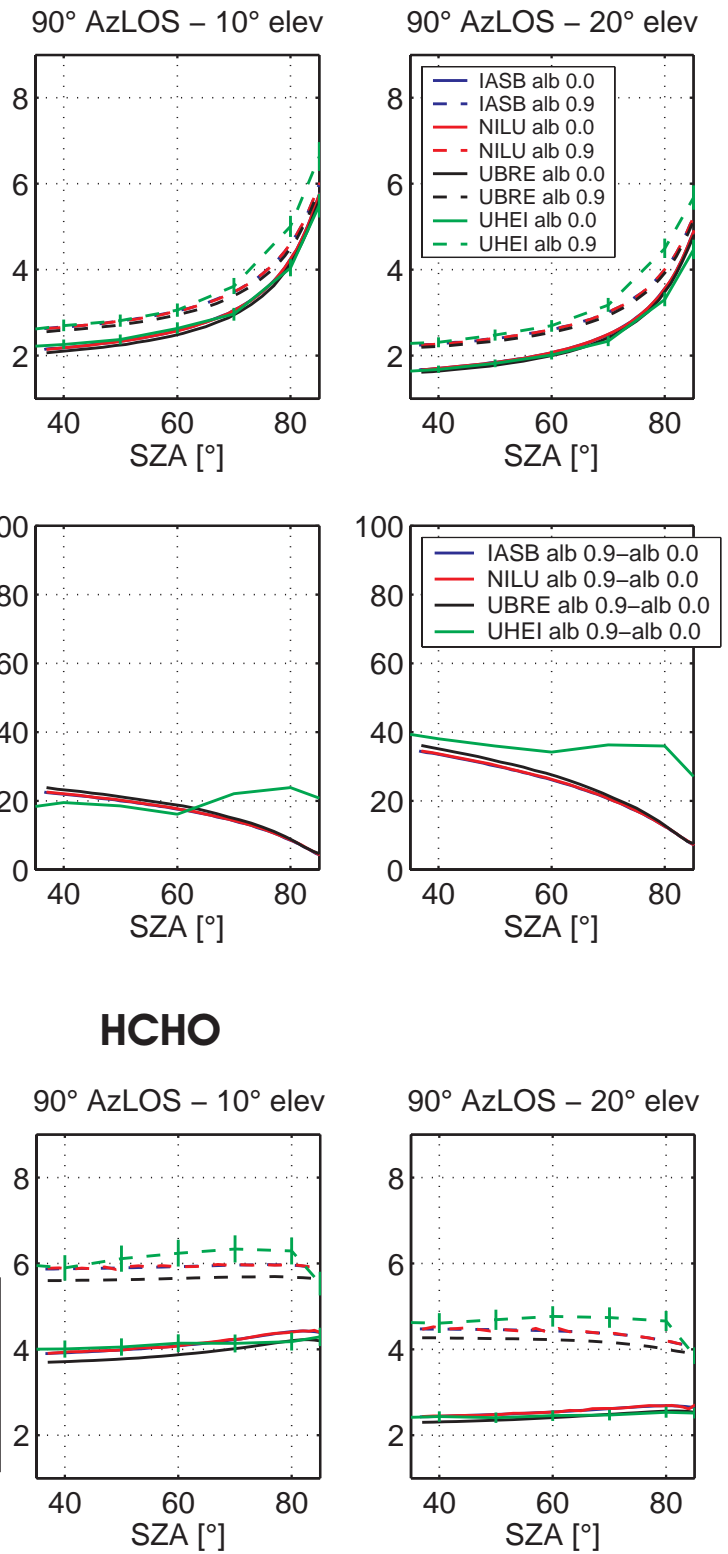

$90^{\circ}$ AzLOS $-20^{\circ}$ elev
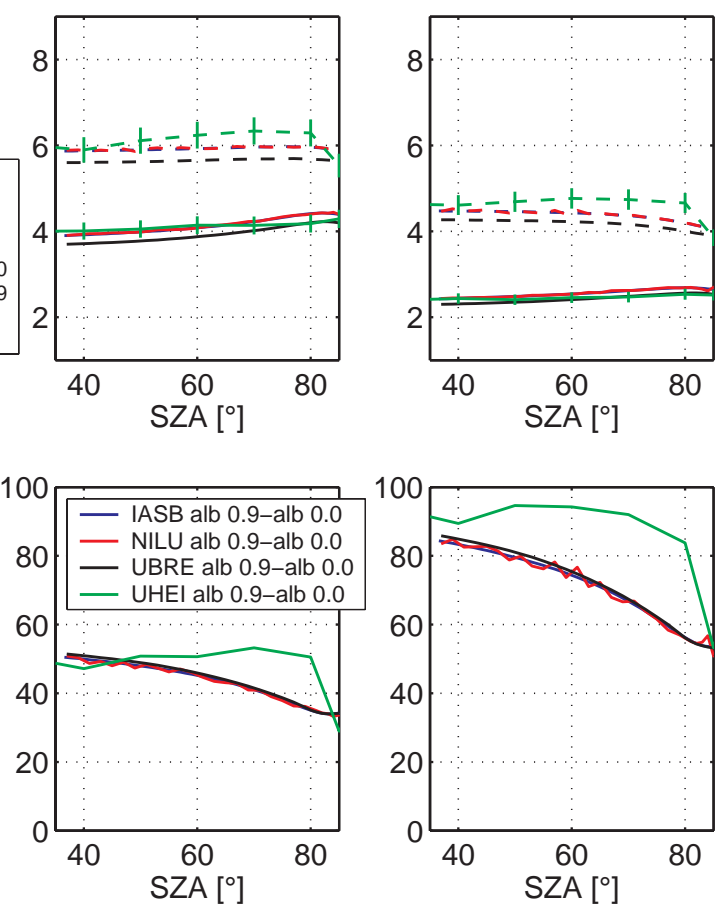

Fig. 10. Impact of the ground albedo on simulated $\mathrm{MAX} \mathrm{NO}_{2}$ and HCHO SCDs. For each species, the upper plots correspond to the SCDs and the lower plots to the relative differences between SCDs calculated with ground albedo values of 0.9 and 0.0 (reference: albedo=0.0). Results for $5^{\circ}, 10^{\circ}$, and $20^{\circ}$ elevation and $90^{\circ}$ AzLOS are plotted here. 
levels of agreement between models in the different comparison tests depend on the assumptions made for the vertical profiles. In case of $\mathrm{NO}_{2}$ and $\mathrm{HCHO}$, very different vertical profiles are indeed possible and could lead to different levels of agreement.

The comparisons of zenith-sky $\mathrm{BrO}, \mathrm{NO}_{2}$, and $\mathrm{OClO}$ SCDs calculated in both single and multiple scattering modes show good overall agreement to a level that is consistent and in some cases better than in the Sarkissian et al. (1995) work. In single scattering mode, the relative difference between the models is smaller than $1 \%$ below $90^{\circ} \mathrm{SZA}$, except for the ISAC-CNR model, for which relative differences rising up to $7.5 \%$ have been found in this SZA range. Above $90^{\circ} \mathrm{SZA}$, the agreement between the IASB, NILU, UBRE, and NIWA models is still very good with a maximum spread of about $2 \%$. Larger discrepancies have been obtained with the ISACCNR model, especially in the OClO SCD calculations (relative difference with the IASB model up to $14 \%$ ). These discrepancies could be partly due to differences in calculating the density in individual atmospheric shells. In multiple scattering mode, the differences between the NILU, UHEI, and UBRE models and the IASB one are smaller than $4.4 \%$ below $90^{\circ} \mathrm{SZA}$ for the three species. Above $90^{\circ} \mathrm{SZA}$, slightly larger discrepancies have been obtained with a maximum relative difference with the IASB model of about $6.5 \%$. As in MAX geometry, the assumptions made on the vertical profiles used for the zenith-sky simulations can have an impact on the agreement found between the models. This is particularly true for $\mathrm{OClO}$, for which a small change in the vertical profiles could change the behaviour of the different models.

The complete set of initialization data (profiles and cross sections sets) and results of this intercomparison exercise have been gathered in a "RT model validation package" enabling the testing of other RT codes aiming to the calculation of SCDs/AMFs. This validation package has been made publicly available through the QUILT project web site (http://nadir.nilu.no/quilt/).

Acknowledgements. This research was financially supported by the European Commission (contract QUILT, EVK2-2000-00545) and the Belgian Federal Science Policy Office (contracts ESAC II EV/35/3A and MO/35/006 \& 012). M. P. Chipperfield (University of Leeds) is acknowledged for providing us with the SLIMCAT data. We would like also to thank the coordinators of the QUILT EC project, B. Arlander and G. O. Braathen (NILU).

Edited by: U. Pöschl

\section{References}

Barbe, A., Marché, P., Secroun, C., and Jouve, P.: Measurements of tropospheric and stratospheric $\mathrm{H}_{2} \mathrm{CO}$ by an infrared high resolution technique, Geophys. Res. Lett., 6(6), 463-465, 1979.

Bruns, M., Buehler, S. A., Burrows, J. P., Heue, K.-P., Platt, U., Pundt, I., Richter, A., Rozanov, A., Wagner, T., and Wang, P.:
Retrieval of profile information from airborne multiaxis UVvisible skylight absorption measurements, Appl. Opt., 43(22), 2004.

Burrows, J. P., Dehn, A., Deters, B., Himmelmann, S., Richter, A., Voigt, S., and Orphal, J.: Atmospheric remote-sensing reference data from GOME: Part 1. Temperature dependent absorption cross sections of $\mathrm{NO}_{2}$ in the 231-794 nm range, J. Quant. Spectrosc. Radiat. Transfer, 60, 1025-1031, 1998.

Burrows, J. P., Richter, A., Dehn, A., Deters, B., Himmelmann, S., Voigt, S., and Orphal, J.: Atmospheric remote-sensing reference data from GOME: Part 2. Temperature dependent absorption cross sections of $\mathrm{O}_{3}$ in the 231-794 nm range, J. Quant. Spectrosc. Radiat. Transfer, 61, 509-517, 1999.

Cantrell, C. A., Davidson, J. A., McDaniel, A. H., Shetter, R. E., and Calvert, J. G.: Temperature-dependent formaldehyde cross sections in the near-ultraviolet region, J. Phys. Chem., 94, 39023908, 1990.

Chipperfield, M. P.: Multiannual simulations with a threedimensional chemical transport model, J. Geophys. Res., 104(D1), 1781-1805, 1999.

Currant, R. and Hilbert, D.: Methods of Mathematical Physics, vol. 2, Interscience, New York, 1962.

Errera, Q. and Fonteyn, D.: Four-dimensional variational chemical assimilation of CRISTA stratospheric measurements, J. Geophys. Res., 106(D11), 12 253-12 265, 2001.

Ehhalt, D. H. and Tönnißen, A.: Hydrogen and carbon compounds in the stratosphere, Proceedings of the NATO Advanced Study Institute on Atmospheric Ozone: Its Variation and Human Influences, edited by: Aikin, A. C., Report No. FAA-EE-80-20, U.S. Federal Aviation Administration, 1979.

Fish, D. J., Jones, R. L., and Strong, E. K.: Midlatitude observations of the diurnal variation of stratospheric BrO, J. Geophys. Res., 100(D9), 18 863-18 871, 1995.

Hendrick, F., Mueller, R., Sinnhuber, B.-M., Bruns, M., Burrows, J. P., Chipperfield, M. P., Fonteyn, D., Richter, A., Van Roozendael, M., and Wittrock, F.: Simulation of BrO Diurnal Variation and BrO Slant Columns: Intercomparison Exercise Between Three Model Packages, Proceedings of the 5th European Workshop on Stratospheric Ozone, Saint Jean de Luz, France, 27 Sept.1 Oct. 1999, Air Pollution Research Report no. 73, European Commission - DG XII, Brussels, 2000.

Hendrick, F., Barret, B., Van Roozendael, M., Boesch, H., Butz, A., De Mazière, M., Goutail, F., Hermans, C., Lambert, J.-C., Pfeilsticker, K., and Pommereau, J.-P.: Retrieval of nitrogen dioxide stratospheric profiles from ground-based zenith-sky UVvisible observations: validation of the technique through correlative comparisons, Atmos. Chem. Phys., 4, 2091-2106, 2004,

SRef-ID: 1680-7324/acp/2004-4-2091.

Heckel, A., Richter, A., Tarsu, T., Wittrock, F., Hak, C., Pundt, I., Junkermann, W., and Burrows, J. P.: MAX-DOAS measurements of formaldehyde in the Po-Valley, Atmos. Chem. Phys., 5, 909918, 2005,

SRef-ID: 1680-7324/acp/2005-5-909.

Hönninger, G., Friedeburg, C. V., and Platt, U.: Multi Axis Differential Optical Absorption Spectroscopy (MAX-DOAS), Atmos. Chem. Phys., 4, 231-254, 2004,

SRef-ID: 1680-7324/acp/2004-4-231. 
Lenoble, J.: Radiative Transfer in Scattering and Absorbing Atmospheres: Standard computational procedures, A. Deepak Publishing, Hampton, Virginia USA, 1985.

Mayer, B. and Kylling, A.: Technical note: The libRadtran software package for radiative transfer calculations - description and examples of use, Atmos. Chem. Phys., 5, 1855-1877, 2005,

SRef-ID: 1680-7324/acp/2005-5-1855.

Noxon, J. F., Whipple, E. C., and Hyde, R. S.: Stratospheric $\mathrm{NO}_{2}$. 1. Observational method and behaviour at midlatitudes, J. Geophys. Res., 84, 5047-5076, 1979.

Petritoli, A., Ravegnani, F., Giovanelli, G., Bortoli, D., Bonafè, U., Kostadinov, I., and Oulanovsky, A.: Off-axis measurements of atmospheric trace gases by use of an airborne ultraviolet-visible spectrometer, Appl. Opt., 41(27), 5593-5599, 2002a.

Petritoli, A., Giovanelli, G., Kostadinov, I., Ravegnani, F., Bortoli, D., Bonasoni, P., Evangelisti, F., Bonafè, U., and Calzolari, F.: Tropospheric and stratospheric $\mathrm{NO}_{2}$ amount deduced by slant column measurements at Mt. Cimone station, Adv. Space Res., 29(11), 1691-1695, 2002b.

Platt, U: Differential optical absorption spectroscopy (DOAS), in: Air Monitoring by Spectroscopic Techniques, Chem. Anal. Ser., edited by: Sigrist, M. W., John Wiley, New York, 127, 27-84, 1994.

Rozanov, A., Rozanov, V.-V., and Burrows, J.-P.: Combined differential-integral approach for the radiation field computation in a spherical shell atmosphere: Nonlimb geometry, J. Geophys. Res., 105, D18, 22 937, 2000.

Rozanov, A., Rozanov, V.-V., and Burrows J.-P.: A numerical radiative transfer model for a spherical planetary atmosphere: combined differential-integral approach involving the Picard iterative approximation, J. Quant. Spectrosc. Radiat. Transfer, 69, 491, 2001.

Rozanov, A., Rozanov, V., Buchwitz, M., Kokhanovsky, A., and Burrows, J. P.: SCIATRAN 2.0. A new radiative transfer model for geophysical applications in the $175-2400 \mathrm{~nm}$ spectral region, Adv. Space Res., 36(5), 1015-1019, 2005.

Sarkissian, A., Roscoe, H. K., Fish, D., Van Roozendael, M., Gil, M., Chen, H. B., Wang, P., Pommereau, J.-P., and Lenoble, J.: Ozone and $\mathrm{NO}_{2}$ air-mass factors for zenith-sky spectrometers: Intercomparison of calculations with different radiative transfer models, Geophys. Res. Lett., 22(9), 1113-1116, 1995.

Schofield, R.: The vertical distribution of atmospheric BrO from ground-based measurements, $\mathrm{PhD}$ thesis, University of Auckland, Auckland, 2003.

Schofield, R., Connor, B. J., Kreher, K., Johnston, P. V., and Rodgers, C. D.: The retrieval of profile and chemical information from ground-based UV-visible spectroscopic measurements, J. Quant. Spectrosc. Radiat. Transfer, 86, 115-131, 2004.

Shettle, E. P.: Models of aerosols, clouds, and precipitation for atmospheric propagation studies, AGARD Conference Proceedings No. 454: Atmospheric propagation in the UV, visible, IR and mm-region and related system aspects, 1989.
Sinnhuber, B.-M., Arlander, D. W., Bovensmann, H., Burrows, J. P., Chipperfield, M. P., Enell, C.-F., Frieß, U., Hendrick, F., Johnston, P. V., Jones, R. L., Kreher, K., Mohamed Tahrin, N., Müller, R., Pfeilsticker, K., Platt, U., Pommereau, J.-P., Pundt, I., Richter, A., South, A. M., Tørnkvist, K.K., Van Roozendael, M., Wagner, T., and Wittrock, F.: Comparison of measurements and model calculations of stratospheric bromine monoxide, J. Geophys. Res., 107(D19), 4398, doi:10.1029/2001JD000940, 2002.

Solomon, S., Schmeltekopf, A. L., and Sanders, R. W.: On the Interpretation of Zenith sky Absorption Measurements, J. Geophys. Res., 92(D7), 8311-8319, 1987.

Spurr, R. J. D.: Linearized Radiative Transfer Theory: A general discrete ordinate approach to the calculation of radiances and analytic weighting functions, with application to atmospheric remote sensing, PhD thesis, Technische Universiteit Eindhoven, 2001.

Stamnes, K., Tsay, S.-C., Wiscombe, W., and Jayaweera, K.: Numerically stable algorithm for discrete-ordinate-method radiative transfer in multiple scattering and emitting layered media, Appl. Opt., 27, 2505-2509, 1988.

Tørnkvist, K. K., Arlander, D. W., and Sinnhuber, B.-M.: Groundbased UV measurements of $\mathrm{BrO}$ and $\mathrm{OClO}$ over $\mathrm{Ny}$-Ålesund during Winter 1996 and 1997 and Andøya during Winter 1998/99, J. Atmos. Chem., 43(2), 75-106, 2002.

von Friedeburg, C.: Derivation of Trace Gas Information combining Differential Optical Absorption Spectroscopy with Radiative Transfer Modelling, PhD thesis, University of Heidelberg, 2003.

Wagner, T., Dix, B., Friedburg, C. v., Frieß, U., Sanghavi, S., Sinreich, R., and Platt, U.: MAX-DOAS $\mathrm{O}_{4}$ measurements: A new technique to derive information on atmospheric aerosolsPrinciples and information content, J. Geophys. Res., 109, D22205, doi:10.1029/2004JD004904, 2004.

Wahner, A., Ravishankara, A. R., Sander, S. P., and Friedl, R.R.: Absorption cross-section of BrO between 312 and $385 \mathrm{~nm}$ at 298 and 223 K, Chem. Phys. Lett., 152, 507-512, 1988.

Wahner, A., Tyndall, G. Y., and Ravishankara, A. R.: Absorption cross-section for $\mathrm{OClO}$ as a function of temperature in the wavelength range from 240-490 nm, J. Phys. Chem., 91, 2735-2738, 1987.

Weidner, F., Bösch, H., Bovensmann, H., Burrows, J. P., Butz, A., Camy-Peyret, C., Dorf, M., Gerilowski, K., Gurlit, W., Platt, U., von Friedeburg, C., Wagner, T., and Pfeilsticker, K.: Balloonborne Limb profiling of UV/vis skylight radiances, ozone and nitrogen dioxide: Technical set-up and validation of the method, Atmos. Chem. Phys., 5, 1409-1422, 2005,

SRef-ID: 1680-7324/acp/2005-5-1409.

Wittrock, F., Oetjen, H., Richter, A., Fietkau, S., Medeke, T., Rozanov, A., and Burrows, J. P.: MAX-DOAS measurements of atmospheric trace gases in Ny-Ålesund - Radiative transfer studies and their application, Atmos. Chem. Phys., 4, 955-966, 2004 ,

SRef-ID: 1680-7324/acp/2004-4-955. 